\title{
LA ADMISIBILIDAD DE LAS PRUEBAS PERICIALES Y LA RACIONALIDAD DE LAS DECISIONES JUDICIALES *
}

\author{
Carmen Vázquez ** \\ Universitat de Girona
}

RESUMEN. En este artículo se analizan diversos criterios de admisibilidad a que puede ser sometida una prueba pericial de parte y que están relacionados con la calidad de la información presentada, las capacidades del juzgador que conocerá del caso y el propio contexto jurídico procesal. Antes se discute si es necesario adoptar medidas paternalistas sobre el juzgador o si es indispensable contar con expertos de origen imparcial a efectos de solucionar parte de los problemas que genera el uso del conocimiento experto en el proceso judicial.

Palabras clave: Prueba pericial de parte, admisibilidad, paternalismo epistémico, imparcialidad.

\section{The Admissibility of Expert Evidence and the Rationality of Judicial Decision-Making}

ABSTRACT. The paper reviews the admissibility of expert evidence offered by parties. It argues about three different criteria involved in the task, which are related with the reliability of the information presented, the judge abilities and the characteristics of the judicial arena. It also analyzes if any kind of epistemic paternalism is necessary or if to look for impartial experts solves at least some of the problems originated by the use of expert knowledge on trial.

Keywords: Expert evidence, admissibility, epistemic paternalism, impartiality, proof.

\footnotetext{
* Fecha de recepción: 30 de julio de 2015. Fecha de aceptación: 22 de septiembre de 2015.

** Para llevar a cabo esta investigación he contado con el apoyo del proyecto de investigación del Ministerio de Economía y Competitividad «Prueba y atribución de responsabilidad: definición y contrastación del daño» (DER2014-52130-P).

Agradezco la cuidadosa lectura de este trabajo y todos sus enriquecedores comentarios a Marcela ARAYA, Carolina Fernández Blanco, Mercedes Fernández López, Jordi FerRer Beltrán, Raymundo Gama, Pedro HADDAD y Diego PAPAYANNIS. Pude exponer una versión previa de este trabajo en el XXI Seminario HispanoFranco-Italiano de Teoría del Derecho en la Universidad de Alicante, por lo que quiero agradecer también a todos los participantes por su fructífero debate.
} 
s un lugar común empezar un artículo con alguna pretensión filosófica sobre el razonamiento probatorio en el derecho diciendo que aun cuando durante mucho tiempo éste no fue objeto del interés de los filósofos, en los últimos años ha crecido significativamente la atención que se le ha dedicado. Sin embargo, es notorio que los análisis que adoptan dicha perspectiva iusfilosófica del razonamiento probatorio se han centrado muy especialmente en la valoración de la prueba y la toma de decisión sobre los hechos, obviando la importancia de decisiones judiciales anteriores como, por ejemplo, la de la admisibilidad de las pruebas que conformarán el conjunto de elementos de juicio del que dispondrá el juez para resolver un proceso judicial.

La atención en la racionalidad de la valoración de la prueba tiene sus raíces en la asunción de que ésta es la mejor garantía de la mayor aproximación entre lo que resulta probado en el procedimiento y la verdad sobre los hechos. Sin embargo, si aceptamos que el objetivo de la prueba en el proceso judicial es la averiguación de la verdad, éste tiene un impacto fundamental en la decisión sobre la admisibilidad de las pruebas: el principio fundamental resultante, llamado principio de inclusión, impone que entre al proceso la mayor cantidad de pruebas relevantes, de tal modo que aumente la probabilidad de que la decisión fáctica del juez sea correcta, i. e., acorde con la verdad sobre los hechos.

El criterio fundamental para decidir la admisibilidad de una prueba es, pues, su relevancia (o, si prefiere, su pertinencia) y ésta está relacionada con la probabilidad de acierto en la decisión ${ }^{1}$. Es decir, el aumento de información relevante puede aumentar la probabilidad de la hipótesis, pero puede disminuirla o incluso no alterarla; sin embargo, pareciera que algo aumenta si disponemos de más información, pues se tiene una base más sólida para fundar la conclusión (KEYNES, 1920: 71)². No abordaré en este trabajo el concepto de relevancia de la prueba, sino que lo daré por presupuesto. Vale la pena decir, sin embargo, la relevancia es una condición necesaria, pero en muchos casos no suficiente para la admisibilidad de cualquier elemento de prueba. En efecto, los sistemas jurídicos han establecido tradicionalmente un cúmulo más o menos extenso de excepciones al principio general de inclusión de las pruebas relevantes, dando como resultado la exclusión de pruebas pese a su relevancia ${ }^{3}$. En definitiva, para que un elemento de prueba sea admisible muchas veces debe satisfacer una variedad de demandas adicionales a la relevancia.

1 Estoy presuponiendo que una prueba es relevante si hace más o menos probable un hecho jurídicamente relevante.

2 En general, los estudiosos de la prueba e incluso algunos ordenamientos vinculan el concepto de relevancia con el de valor probatorio y, con ello, se alude a la probabilidad de la hipótesis fáctica que se pretende probar. Un excepción a esto es FERRER (2007: 68) quien también considera que «cuánta más información relevante está a disposición de quien debe decidir, mayor probabilidad de acierto en la decisión». Está aquí presupuesta una distinción planteada por KEYNES (1920: 71) en la comparación cuantitativa de argumentos entre el aumento de probabilidad de acierto en la decisión y el aumento de la probabilidad de la hipótesis sobre los hechos a probar.

3 Quizá en los sistemas de derecho romano-germánico la que más atención ha recibido en los últimos años sea la de la licitud de la prueba, excluyéndose, entonces, toda prueba ilícita pese a su relevancia. Ahora bien, tampoco es extraño que en diversos sistemas, como el español, por ejemplo, la exclusión de la prueba ilícita se determine en la sentencia del caso y no en una etapa previa del procedimiento. 
Las reglas que imponen estas excepciones contribuyen de forma decisiva a lo que FERRER (2007: 42) considera «la clave de la especificidad jurídica de la prueba jurídica [radicada en que] el conjunto de los elementos a valorar es un subconjunto del conjunto formado por la totalidad de los elementos disponibles». En términos generales, esto es así por diversas limitaciones procesales como los plazos temporales para la presentación de pruebas o la participación de las partes en la conformación de ese subconjunto. Pero, ¿tienen cabida otros criterios de admisibilidad de las pruebas que faciliten la averiguación de la verdad?, y ¿qué justificación encontramos en aquellos criterios que obstaculizan de alguna manera la averiguación de la verdad?

Como es bien sabido, las decisiones de admisibilidad se realizan respecto de cada una de las pruebas que son ofrecidas y a ellas se aplican algunos criterios generales y otros específicos para algunos tipos de prueba. En este trabajo dedicaré mi atención a los requisitos específicos que versan sobre un medio de prueba que en los últimos años ha adquirido gran protagonismo en el escenario procesal: la prueba pericial. Mi decisión no se funda sólo en ese papel protagónico sino también porque se ha considerado que al ser una prueba supuestamente distinta al resto de elementos de juicio amerita un tratamiento diferente sobre todo respecto su admisibilidad. Así pues, para responder a las dos preguntas planteadas en el párrafo anterior me ceñiré al análisis de diversos criterios que se han considerado para la admisibilidad de las pruebas periciales.

Quienes están familiarizados con el tema del conocimiento experto en el proceso judicial saben que la sentencia de la Corte Suprema estadounidense en el caso Daubert v. Merrell Dow Pharmaceuticals, Inc. ${ }^{4}$ constituye un hito en el análisis de las pruebas periciales y que su influencia ha rebasado fronteras, siendo múltiplemente «trasplantada» a otros sistemas jurídicos con características diversas. Precisamente una de las consecuencias positivas que ha tenido el interés teórico suscitado en los países de tradición romano-germánica por dicha sentencia es la puesta en la agenda de la admisibilidad y algunos de los posibles criterios para determinarla.

En los países del common law las reglas de admisibilidad suelen ser vistas como una técnica probatoria para controlar la calidad de la información con que decidirá el juzgador de los hechos, quien no tiene la obligación de motivar sus decisiones y, por ello (aunque no sólo por ello), la sentencia del caso Daubert estableció una serie de indicios que los jueces podrían observar para tomar la decisión de admitir o excluir una prueba pericial en función de su calidad ${ }^{5}$. No me interesa aquí ahondar en esos indicios ni en detalles del sistema estadounidense o su experiencia con la prueba pericial ${ }^{6}$; mi interés, más bien, se enfocará en plantear un panorama más general sobre los posibles controles a implementar en esta etapa probatoria como decisiones previas que pueden

4 Daubert v. Merell Dow Pharms., Inc. (Daubert III), 509 U.S. 579 (1993).

5 Al respecto, puede consultarse ROBERTS y ZuCKERMAN, 2004: 305. Y, ésta, desde luego, es una diferencia importante con nuestros sistemas, en donde la calidad de las pruebas es objeto de la valoración de las mismas (y no de su admisión).

Por otro lado, vale la pena notar la incongruencia (generalizada) al buscar criterios pretendidamente objetivos para la valoración de la prueba pericial y, a la vez, defender modelos de la toma de la decisión final sobre los hechos basados en la consciencia, las creencias o la convicción subjetiva del juez que decide el caso. Por el contrario, un modelo congruente, y correcto, debería optar por concebir en ambos niveles pautas de racionalidad acordes con el objetivo de la institución probatoria: la averiguación de la verdad.

6 Ése es parte del objetivo de otro trabajo, VÁZQUEZ (2015); vid. concretamente el capítulo 2. 
resultar determinantes para la práctica y la valoración de estos elementos de prueba (incluido, por ejemplo, si es necesario controlar de alguna manera la calidad de las pruebas periciales para su admisión).

Para ello me centraré fundamentalmente en la prueba pericial de parte. Dejo de lado a la prueba pericial que es realizada por un experto seleccionado de alguna manera por el juez ${ }^{7}$, dado que en esta categoría de pruebas periciales el juez no necesariamente hace un juicio de admisibilidad en sentido estricto, sino que decide designar al perito correspondiente (aunque sea, en ocasiones, a petición de alguna de las partes) ${ }^{8}$.

Una vez delimitado el tema y mis objetivos, sugiero el siguiente itinerario. Antes he dicho que se ha llegado a considerar a la prueba pericial como una prueba distinta al resto, dicha diferencia se hace radicar en que el juez no tiene los conocimientos expertos necesarios para evaluar adecuadamente al perito. Bajo este supuesto se han planteado, al menos, dos posibles estrategias que es necesario analizar primero: el paternalismo epistémico y la imparcialidad del perito. El primero suele ser concebido como un mecanismo de exclusión de información con la pretensión de evitar malas decisiones por parte del juzgador de los hechos; el segundo, como un criterio suficiente para justificar el uso de información experta en la decisión fáctica y, por ello, también como una característica de los expertos a proteger desde su admisión a juicio.

Tanto el paternalismo epistémico como la imparcialidad del perito resultan una especie de meta-criterio que podrían subordinar de una u otra manera el tratamiento de la prueba pericial desde su admisibilidad. Sin embargo, el objetivo de este trabajo es cuestionar los posibles fundamentos del paternalismo epistémico e identificar diversos sentidos de «(im)parcialidad» que ameritan un tratamiento diverso en las distintas etapas procesales. Hecho esto, entonces, analizaré posibles criterios (adicionales a la relevancia) que podrían usarse para decidir la admisibilidad de la prueba pericial y que tienen que ver con el sujeto que decide, la calidad de la información experta que pretende introducirse y el contexto jurídico-procesal en que tienen lugar.

\section{EL PATERNALISMO EPISTÉMICO}

REDMAYNE (1998: 6) asocia la decisión de admitir o excluir pruebas periciales de parte a la concepción que se tenga sobre las capacidades cognitivas del juzgador de los hechos para atribuirle a las pruebas el valor que les corresponde, distinguiendo entre un modelo de confianza en el juzgador de los hechos y otro de desconfianza en él. Así, se establecerían controles de admisión de estos elementos de juicio si y sólo si se desconfía de las capacidades cognitivas del juzgador. Dicha desconfianza se muestra

7 El perito de confianza del juez, en mi opinión, constituye una categoría distinta. Su distinción radica precisamente en su designación y es que considero que el nombramiento de este tipo de peritos debería hacerse teniendo el juez ya razones para creer en él; y tales razones se deben fundamentar en la confiabilidad del perito. De ahí que prefiera llamarlos «peritos de confianza de los jueces» y no «peritos oficiales» o «peritos del juez». Sin embargo, esto no será objeto de análisis de este trabajo.

8 Cuando las partes solicitan al juez que nombre un perito porque consideran que ciertos conocimientos expertos son relevantes para la toma de decisión sobre los hechos, entonces sí que cobra sentido hablar de un juicio de admisibilidad por parte del juez. 
especialmente en los sistemas del common law, donde se suele presuponer un juzgador de los hechos pasivo, que no tiene facultad para preguntar al experto (éste es preguntado frente al jurado, mas no por el jurado mismo) y, por ello, se pretende asegurar que la deferencia que un juzgador de los hechos pueda tener hacia las pruebas periciales se dirija al menos hacia pruebas sólidas (REDMAYNE, 2001: 125 y ss.) ${ }^{9}$.

La desconfianza en las facultades cognitivas del juzgador de los hechos (como categoría, no en concretos individuos) podría resultar en al menos dos tipos de decisiones: cambiar a los sujetos que deciden intentando tener sujetos más capacitados para realizar tal tarea o adoptar decisiones paternalistas sobre las decisiones del sujeto que realiza dicha tarea. La primera estrategia supone cuestionar categorías de sujetos, no individuos en particular (por ejemplo, los jurados o los jueces, etc.) y pretendería cambiar precisamente a tales decisores $(v$. gr. que ya no decidan los jurados sino los jueces, que ya no decidan los jueces sino los expertos, etc.) La segunda estrategia es identificable bajo el rótulo de paternalismo epistémico y pretende proteger al decisor de sus malas decisiones guiando de alguna manera la propia toma de decisión.

El paternalismo epistémico se ha venido sugiriendo en el ámbito de la prueba pericial como una política hacia los juzgadores de los hechos para protegerles de ellos mismos, dado el supuesto impacto que podría causar en su razonamiento la admisión de elementos de juicio de carácter experto ${ }^{10}$, pese a la relevancia de éstos para la resolución del caso en cuestión. GOLDMAN (1991) hace referencia de la siguiente manera al paternalismo epistémico hacia los juzgadores de los hechos:

$\mathrm{Si}$, en opinión de los legisladores, una cierta categoría de elementos de juicio suele inducir al jurado a error, ellos están facultados para exigir o permitir que tales pruebas se mantengan fuera del alcance de los jurados. Éste es un ejemplo de lo que llamo paternalismo epistémico. [...] El tribunal sustituye con su propia expectativa sobre el error del jurado la expectativa del jurado mismo, quienes quizá hubiesen [habiendo estado facultados para hacerlo] aceptado información sobre el carácter del acusado, sus antecedentes penales o sobre su retractación de un reconocimiento de culpabilidad previo, considerando que probablemente reduciría su probabilidad de error.

Es decir, bajo el presupuesto de que en determinadas condiciones el juzgador de los hechos cometerá errores, por ejemplo, porque sus miembros pueden tener un background conformado por creencias falsas o porque su habilidad para sacar conclusiones adecuadas de las pruebas es más bien deficiente, entonces se limita su autonomía epistémica con el fin de obtener resoluciones verdaderas sobre el caso en cuestión. En el ejemplo citado por GOLDMAN, dicha limitante es impuesta por el legislador y ejerci-

9 La descripción del jurado como un juzgador de los hechos pasivo no alude a una voluntad de éstos para permanecer de tal forma, evidentemente, sino al cúmulo de reglas que evitan conductas que consideraríamos razonables fuera del ámbito jurídico procesal, como hacer las preguntas necesarias cuando haya dudas o hacer inferencias a partir de determinados hechos, etc. Vid. LAUDAN (2006) para un análisis sobre estas cuestiones en materia penal en los Estados Unidos.

En España, por ejemplo, la Ley Orgánica del Poder Judicial en su art. 46.1 sí permite a los jurados plantear preguntas a los peritos, aunque éstas se realizan a través del magistrado que preside el juicio, previa su evaluación de la pertinencia de éstas.

10 La idea de «protegerse de ellos mismos» es de HART (1966: 123). Aunque HarT se refería al paternalismo concerniente al razonamiento práctico, la idea es aplicable en términos generales al tipo de paternalismo relacionado con el razonamiento teórico, que es el que aquí nos interesa. 
tada por un juzgador profesional que «protege» al jurado de sí mismo seleccionando la información que éste conocerá ${ }^{11}$.

Éste es precisamente el ejemplo paternalista en que me centraré, dado que es la estrategia sugerida por varios teóricos [como, por ejemplo, DuCE (2010: 48 y 2013: 55)o GASCÓN, LuCENA y GONZÁLEZ (2010: 12)]. Por supuesto, podrían discutirse los medios mediante los cuales se ejercería, en caso necesario, el paternalismo epistémico en el ámbito probatorio, entre los cuales, pueden concebirse al menos los tres siguientes:

a) Que el juzgador de los hechos no tenga conocimiento alguno de la existencia de ciertas pruebas.

b) Que aunque conozca de su existencia, no tenga contacto con ellas, i.e., no conozca la información que aportan.

c) Que teniendo conocimiento de su existencia y contacto con ellas, se indique al juzgador de los hechos el valor probatorio que le debe asignar.

Evidentemente la primera de las estrategias es la más contundente, eliminando cualquier posibilidad de «contaminación» por parte del juzgador de los hechos ${ }^{12}$. Y, en cambio, dentro de la tercera opción y como un medio menos costoso podría pensarse en que se le diesen al juzgador de los hechos algunas instrucciones concretas sobre las pruebas en cuestión sin que éstas sean excluidas. Sin embargo, cuando se plantean acciones paternalistas en el tema de la prueba pericial se considera fundamentalmente la primera estrategia y de aplicación a todos los jueces ${ }^{13}$.

En el ámbito del proceso judicial estadounidense, autores como por ejemplo LEITER (1997) y ALLEN y LEITER (2001) han defendido que ciertas reglas probatorias de su sistema no están diseñadas para «conocedores ideales» sino para «conocedores reales», por lo que éstas:

toman en cuenta las deficiencias epistémicas de los jurados, tales como su susceptibilidad a la confusión y el prejuicio o su generalmente modesto nivel de habilidad intelectual. [...] La regla probatoria que excluye pruebas no-científicas es una regla epistémica primaria en el sentido en que se establece asumiendo que los jurados deben ser «protegidos» de la ciencia basura en la formación de creencias sobre los hechos en disputa.

11 Aunque bien podría sostenerse que en el caso de un proceso judicial el objeto de protección serían las partes en litigio y/o la sociedad en general (GOLDMAN, 1991), creo bastaría con sostener, como en todo paternalismo epistémico, que el interés es la verdad (o la formación de creencias verdaderas) con relativa independencia de los posibles fines epistémicos de los sujetos de la relación.

12 Vale le pena llamar la atención sobre el hecho de que en sistemas que obligan al juzgador a motivar sus decisiones, la supuesta contaminación aún podría ser controlable sin necesidad de excluir elementos de juicio por ello. Esto obviamente presupondría un correcto funcionamiento de la motivación: que de hecho los jueces justifiquen sus decisiones y no que únicamente expliquen el íter mental que les llevó a tomar una decisión o, peor aún, que únicamente hagan una especie de resumen con el contenido las pruebas, etcétera.

Por otro lado, conocer la justificación que brinda un juzgador sobre las decisiones judiciales que toma permitiría también hacer diversas investigaciones empíricas, entre ellas, saber cómo de hecho valoran los jueces las pruebas periciales en general.

13 No se habla de un juzgador en concreto, sino de los juzgadores en general y de una estrategia normativa. En este sentido, por ejemplo, LEITER (1997: 803) define el paternalismo en función de las reglas: «El paternalismo en cualquier ámbito de la regulación jurídica supone que las reglas deben sustituir los juicios de los agentes mismos por el juicio de los legisladores acerca de qué es lo mejor para esos juicios. El paternalismo epistémico sustituye con el criterio de los legisladores respecto a qué es lo mejor epistémicamente para los agentes en su propio juicio». 
Entre los problemas teórico-prácticos que pueden plantearse en esta discusión se encuentra el concepto de «paternalismo», su justificación, y los aspectos particulares que caracterizarían al paternalismo epistémico ${ }^{14}$. La primera cuestión es ya un complejo debate que supera con mucho mis objetivos, me basta aquí con tener una noción de paternalismo que permita plantear el escenario de los problemas a abordar; para ello adoptaré el esquema planteado por ALEMANY (2005: 273), dada su claridad y sencillez:

El agente A ejerce paternalismo sobre B si y sólo si:

1) A ejerce poder sobre $B$,

2) con la finalidad de evitar que $B$ lleve a cabo acciones $u$ omisiones que le dañan a sî mismo y/o le suponen un incremento del riesgo de daño ${ }^{15}$.

Bajo este esquema, diríamos que el modo en que se ejerce la acción paternalista es siempre un «ejercicio de poder». Pese al debate que pueda generar la propia noción de «poder», basta aquí con suponer que cualquier ejercicio de éste por A se orienta intencionalmente a la obtención de algún comportamiento de $\mathrm{B}$ y que $\mathrm{A}$ puede ser responsabilizado de dicho ejercicio ${ }^{16}$. Una discusión distinta es cuáles son o deberían ser los concretos medios por los cuales se lleva a cabo dicho ejercicio de poder, $v$. gr. el engaño, la coacción, etcétera.

Respecto al numeral dos, como bien dice ALEMANY, no todo ejercicio de poder es paternalista, así que es necesario considerar la finalidad concreta de dicho ejercicio: evitar un daño ${ }^{17}$, básicamente diferenciándolo del objetivo de la promoción de intereses más allá de cierto umbral mínimo o de intereses ulteriores.

Siguiendo entonces el esquema de AlEMANY, diríamos que también en el ámbito probatorio una acción paternalista epistémicamente es un ejercicio de poder y el agente que la ejerce debería poder ser responsabilizado. Por ello, por ejemplo, las partes al no tener poder sobre el juez no podrían ejercer acciones paternalistas. ¿Quién podría ejercerlas? La respuesta dependerá de la estructura orgánica prevista en cada sistema procesal; pero, obviamente tendrá que hacerse por un agente distinto a aquel en quien recae la medida paternalista, es decir, del juzgador de los hechos.

En cuanto al daño que se trataría de evitar mediante el paternalismo epistémico sería, precisamente, un daño epistémico (o de origen epistémico): la toma de una decisión probatoria incorrecta dado su fundamento en una creencia falsa. Así, podría de-

14 Puede verse un análisis sobre el paternalismo jurídico, en castellano, en GARZÓN VALDÉS (1993); AtienZa (1988); Alemany (2005 y 2006); y, más recientemente, MANiACI (2012).

15 Pese a que, además de no considerar al paternalismo epistémico entre los tipos de paternalismo que identifica, Alemany (2005: 272) dice explícitamente que «[su] propuesta es, en todo caso, restringir el uso del término paternalismo a la evitación de daños físicos, psíquicos y/o económicos», aquí extenderé esa idea a daños producidos por ciertos tipos de errores cognoscitivos.

Por otro lado, para otras discusiones sobre la definición de «paternalismo», cfr. SARTORIUS, 1983; FeINBERG, 1986; GARZÓN VALDÉS, 1993; G. DwORKIN, 2002.

16 En términos generales éste es el planteamiento de Alemany (2005: 268 y ss.) que, para tales efectos, recurre a la distinción entre «poder» e «influencia» de R. ZIMMERLING. Así, termina afirmando que explica el ejercicio del poder como aquel orientado intencionalmente a obtener un comportamiento de otro; que es posible ejercer el poder por medio de la influencia; y que el ejercicio del poder conlleva responsabilidad por parte de quien lo ejerce, aun cuando dicho poder se ejerza mediante la influencia.

${ }_{17}$ Qué es un daño es una cuestión también debatible. Algunos lo identifican como un perjuicio a un interés legítimo, otros a la frustración de expectativas legítimas y, una tercera vía, como una acción contraria a los derechos de un individuo (J. L. Coleman, 1992: 288). 
cirse que una acción es paternalista epistémicamente si tiene como objetivo evitar que $\mathrm{B}$ razone incorrectamente sobre qué cuenta a favor de una creencia, dado que hacerlo supondría un incremento del riesgo de error. Entonces, por ejemplo, no buscaría imponer el uso del casco a los motociclistas para protegerles evitando un daño, sino que el motociclista no considere cierto tipo de información que supuestamente le llevaría a creer (erróneamente) que dejar de usar casco no es peligroso ${ }^{18}$.

Obsérvese que lo anterior supone el objetivo de llegar a la verdad en el ámbito probatorio y, por ello, la finalidad de una acción paternalista epistemológicamente debería ser evitar incrementos en el riesgo de error (como la formación de creencias (alsas) ${ }^{19}$.

Pero, ¿cuándo está justificada una acción paternalista? Antes de responder a ello, vale la pena notar que «paternalismo» es un concepto neutro, no intrínsecamente valorativo, $i$. e., no es ni positivo ni negativo en sí mismo ${ }^{20} ; \mathrm{y}$, esta neutralidad genera como resultado la distinción entre paternalismo justificado e injustificado. Podría hablarse de al menos dos tipos de justificación no necesariamente coincidentes, una a priori y otra a posteriori. Una justificación a priori se orientaría a presentar como aceptables este tipo de políticas sobre un sujeto, dado que éstas le evitarían daños dada su incapacidad, déficit, debilidad o incompetencia relevante; mientras que una justificación a posteriori del paternalismo, dependería de una evaluación de los resultados o consecuencias, es decir, de si se lograron los fines buscados ${ }^{21}$.

Me interesa aquí fundamentalmente el primer tipo de justificación, aquella que atiende a las características, estado o situación del individuo a efectos de ejercer cierto paternalismo epistémico sobre él y, como ya resulta obvio, concretamente en lo que hace a la prueba pericial.

Una pregunta que salta de inmediato es dónde radicaría la incapacidad de los juzgadores de los hechos, $i$. e., de qué incapacidad se está hablando. En general, podría decirse que los factores relevantes a considerar serían cierto estado o condición del sujeto que supongan límites o déficits cognitivos traducibles en una tendencia al

18 Así, por ejemplo, cuando GOLDMAN (1991: 119) piensa «en controladores de la comunicación que ejercen un paternalismo epistémico siempre que interpongan su propio juicio en lugar de permitir a la audiencia ejercer el suyo (todo ello asumiendo los objetivos epistémicos de la audiencia)», sólo tiene sentido si entendemos que está hablando exclusivamente del razonamiento teórico. De lo contrario, todo paternalismo sería «epistémico» y no cabría distinguir a éste como una especie del género «paternalismo».

19 No toda creencia falsa necesariamente afecta a la búsqueda de la verdad. Piénsese como ejemplo en la revisión en segunda instancia de exclusión de pruebas, cuya posibilidad de obtener una decisión favorable depende de si se puede comprobar que tal prueba fue considerada por el juzgador de los hechos al momento de tomar su decisión. Vale recordar que en los juicios seguidos ante jurado que no tienen obligación de motivar su decisión, esto es imposible y por ello el procedimiento es distinto.

20 Al respecto consúltese VAN DE VEER (1986: 16 y ss.). Y, en cambio, para una definición intrínsecamente evaluativa, vid. DWORKIN, 1972.

21 A este tipo de justificación parece referirse GoLDMAN (1991). Es importante notar, como lo hace G. DWORKIN (2002), que «podría creerse que la pregunta sobre si se produce más bien que daño es simplemente una pregunta empírica. Depende de nuestro entendimiento sobre aquello que es benéfico para la persona. Si el bien incluye simplemente cuestiones como una larga vida, mayor salud, más ingresos o menos depresión, entonces sí que pareciera ser empírico. Pero si uno concibe que el bien de los individuos incluye cuestiones como ser respetado como un agente independiente, tener el derecho de tomar las decisiones por uno mismo o que no se infrinja la autonomía personal, entonces la pregunta sobre si un agente está mejor después de haber sido sujeto a cierto paternalismo es una cuestión en parte normativa». 
error. Obsérvese que no se trata simplemente de errores ocasionales ${ }^{22}$, sino de una cuestión más bien sistemática e incluso predecible. Y, claro, también deben diferenciarse estos errores de aquello que sobre juzgadores particulares enuncia DEVIS ECHANDÍA (1972: 61):

[...] el riesgo de la pereza física y mental de algunos juzgadores, que no hagan uso de la facultad legal para criticar [a la prueba pericial], sino que se faciliten el trabajo rindiéndole un exagerado servilismo. Pero este riesgo existe igual con otros medios de prueba [que] pueden ser aceptados servilmente o sometidos a rigurosa crítica, según la competencia y la preparación de cada juez. [...] [Es] por esta razón que no puede esgrimirse este peligro como algo exclusivo de la moderna prueba técnica o científica.

De cualquier manera, primero habría que saber qué capacidades cognitivas podrían considerarse relevantes a efectos de analizar si los actuales decisores son o no cognitivamente competentes para realizar la función que se les ha atribuido, es decir, valorar las pruebas periciales (teniendo en cuenta, desde luego, que no se le pide al juez que compruebe o rehaga las operaciones periciales). Al respecto, por ejemplo, DwYER (2008: 108) considera que dado que al juzgador se le exige únicamente que acepte (o no) una prueba pericial, y no que la produzca ${ }^{23}$, sólo tiene que valorar la calidad de la inferencia hecha inductivamente a partir de los hechos. Lo que, en su opinión, es considerablemente menos demandante epistemológicamente, pues bastaría con determinar que las decisiones inferenciales del experto son razonables ${ }^{24}$.

Pero, aún más, una vez identificada la incapacidad relevante que se atribuya a los juzgadores de los hechos, la justificación del paternalismo epistémico exigiría disponer de datos empíricos sólidos que muestren la existencia de esa incapacidad, y no meras suposiciones al respecto. En el contexto anglosajón se han realizado ya varios estudios con el objetivo de comprobar o refutar que los jurados como juzgadores de los hechos son fácilmente impresionables cuando se les presenta una prueba etiquetada como «científica». Nótese que la incapacidad relevante aquí no es el seguimiento de inferencias como supone DWYER, sino una sobrevaloración de un tipo de pruebas periciales. Y los resultados de dichos estudios son contradictorios, de modo que mientras algunos confirman la hipótesis otros la refutan ${ }^{25}$.

22 Las causas de estos errores podrían ser sumamente variadas, como la mala memoria, la falta de atención, ciertas predisposiciones emocionales, la complejidad del caso o, incluso, la falta de habilidades de un juzgador concreto para cuestionar, etcétera.

23 Lo que, en opinión de DWYER (2008: 108), implicaría que el experto que realiza la inferencia correspondiente identifique los elementos probatorios relevantes, tome decisiones apropiadas sobre las inferencias que podrían ser hechas a partir de tales elementos y asigne probabilidades adecuadas a éstas, además de establecer relaciones entre ellas.

24 Dudar de la capacidad de los jueces para realizar inferencias tendría consecuencias que van mucho más allá de la prueba pericial, si aceptamos que todo el razonamiento probatorio es inferencial probablemente tendríamos que empezar a pensar en otro tipo de decisores o quizá de distintas estrategias normativas sobre la institución probatoria.

En el contexto jurídico-procesal, la capacidad natural ordinaria del ser humano para hacer deducciones y/o inferencias probabilísticas en general se ha discutido para justificar la libre valoración de la prueba; por ejemplo, desde la psicología se han hecho investigaciones sobre patrones sistemáticos o tendencia sistemática de error cognitivo en el razonamiento ordinario, $v$. gr. la falacia de la afirmación del consecuente o la no consideración de probabilidades a priori. Al respecto, vid. un brillante artículo sobre la libertad en la valoración de las pruebas y su legitimidad en COHEN (1983).

25 Puede verse un listado sumamente completo e interesante de los distintos tipos de estudios realizados en Estados Unidos en Schauer y Spellman (2013). 
Por lo que hace al contexto romano-germánico, ningún estudio de corte empírico ha sido realizado, que yo conozca, limitándose algunos autores a citar, como mucho, estudios realizados en el mundo anglosajón. Y ello sin tomar en consideración las características de los tipos de juzgador prevalecientes en uno y otro sistema, pese a que bien podría haber diferencias importantes entre un juzgador profesional y un jurado lego a efectos de identificar las deficiencias relevantes, por ejemplo. Y también en el ejercicio de las medidas paternalistas, considerando que en nuestros sistemas la gran mayoría de las veces la admisibilidad de las pruebas se decide por el mismo sujeto que las valora o, bien, que tanto el juez que admite pruebas como el que las valora son juzgadores profesionales.

Entonces, para concluir con el paternalismo epistémico, si no tenemos información empírica sólida sobre las incapacidades relevantes que dé sustento al ejercicio de poder que constituye una medida paternalista, antes de cuestionar con meras suposiciones las capacidades de los jueces para valorar la prueba pericial, habría que preocuparse por ofrecerle mecanismos procesales adecuados para mejorar su situación cognoscitiva y facilitar su labor cuando se trata de pruebas periciales (desde luego no sólo respecto de éstas). Y si hecho esto se llegase a justificar alguna medida paternalista, aun cabría debatir qué acciones paternalistas son las más adecuadas, pues no necesariamente consisten en excluir pruebas que puedan aportar información relevante.

\section{LA IMPARCIALIDAD DE LOS PERITOS}

En los sistemas de tradición romano-germánica uno de los criterios más usados, tanto para decidir la admisión de pruebas periciales como para su valoración, ha sido la imparcialidad del perito, entendida, en términos sumamente generales, como la ausencia de un tipo de relación con las partes. Dicha relación podría establecerse, por ejemplo, por la forma en que es seleccionado el perito o incluso por quién debe pagar sus honorarios o en función del acuerdo entre las partes en el contenido del peritaje, etcétera.

Tanto la jurisprudencia como la dogmática suelen derivar de esa ausencia de relación del perito con una de las partes una serie de consecuencias sobre el contenido o resultado de la prueba pericial, sin explicitar mayor fundamento para la inferencia respectiva. Como ejemplo consideremos la sentencia del Tribunal Supremo español de 5 de noviembre de 1998:

Todo acto declaratorio de ruina legal encuentra su causa en una situación de hecho para cuya apreciación son esenciales los informes periciales, a valorar — art. 632 de la Ley de Enjuiciamiento Civil - a la luz de las reglas de la sana crítica, siendo uno de los criterios básicos a tener en cuenta, el de la independencia de los técnicos autores de los informes, respecto a los intereses en juego, lo que, desde luego, viene a servir de suficiente garantía a la imparcialidad de sus apreciaciones, siendo evidente que conforme a ese criterio, los dictámenes presuntamente más objetivos son, en principio, los de los técnicos municipales y los de los peritos procesales nombrados por insaculación o por acuerdo entre las partes...

O el criterio histórico también de la jurisprudencia española que afirma que «deben preferirse los dictámenes [emitidos] por organismos oficiales o por peritos no designados por las partes»; «que la pericia judicial se antoja más objetiva e impar- 
cial que la pericial de parte, la cual adolece de excesiva complacencia para quien la contrató» ${ }^{26}$.

Y, en la dogmática, BOTTER (1982: 84), entre otros muchos, enumera las supuestas ventajas que tiene un perito imparcial de designación judicial: ayuda al juez de los hechos a llegar a un resultado correcto, aumenta la predictibilidad de las decisiones, ayuda en la valoración del caso, pone a disposición expertos cualificados y fiables que, de otra manera, se rehusarían a participar y provee de un peritaje que disminuirá el tiempo del proceso. No hace falta mucho para advertir los non sequitur del argumento de BOTTER; así, por ejemplo, un perito imparcial podría generar resultados incorrectos, un perito imparcial podría no ser el más cualificado para el caso concreto, etcétera.

Sin embargo, centrar la atención únicamente en la imparcialidad obvia muchos de los problemas periciales más importantes que surgen en un proceso judicial: los desacuerdos genuinos entre expertos ${ }^{27}$; los posibles errores cognitivos (de buena fe, si se quiere agregar) del perito imparcial; y, por supuesto, la incompetencia de muchos supuestos peritos que podrían ser completamente imparciales.

Pero, un problema básico es que ninguno de estos autores ni criterios jurisprudenciales toma en cuenta la ambigüedad del término «parcialidad» (y correspondientemente de su antónimo «imparcialidad»). En mi opinión, es posible distinguir al menos tres posibles sentidos de «parcialidad»:

a) Como relación directa con una de las partes por su selección.

b) Como disposición motivacional para favorecer a alguien.

c) Como la presencia de sesgos cognitivos dadas ciertas predisposiciones cognitivas y/o información deficiente ${ }^{28}$.

Haré referencia a estos tres sentidos como parcialidad de origen, parcialidad disposicional y parcialidad cognitiva, respectivamente ${ }^{29}$. Como se verá, en mi opinión, sólo las dos primeras son abordables en la admisibilidad de las pruebas periciales, mientras la última lo es en la práctica de éstas; al no distinguirse los distintos sentidos de «imparcialidad», por ejemplo, se termina convirtiendo una característica intrínseca de la pruebas periciales de parte (parcialidad de origen) en una cuestión que injustificadamente termina disminuyendo su valor probatorio.

26 Sentencia de 21 de junio de 1983 del Tribunal Supremo español y STS de la Audiencia Provincial de Valencia de 1 de diciembre de 2004 respectivamente. También puede verse, por todos, LóPEZ-MuÑIZ GOÑI (2008: 368-377) y ABEL LLUCH (2009: 140 y ss.), citando además amplia jurisprudencia española sobre esta preferencia.

${ }^{27}$ La distinción de los diversos sentidos de parcialidad permite un análisis más completo del problema de los desacuerdos entre peritos, que suele verse exclusivamente como el resultado de la relación de al menos uno de ellos con alguna de las partes (parcialidad de origen). Sin embargo, no todo desacuerdo entre expertos tiene que ver con un tipo de parcialidad y no necesariamente debe haber desacuerdo entre peritos que tengan, por ejemplo, una parcialidad de origen. Pensar en los desacuerdos como algo que sólo se da cuando hay algún tipo de parcialidad no permite explicar, y tal vez mucho menos prever mecanismos para afrontar, un desacuerdo entre dos peritos imparciales de origen, situación que pareciera ser común en la práctica.

28 Es importante diferenciar, en la medida de lo posible, las preconcepciones de los prejuicios. Podría decirse que las primeras están relacionadas con cómo conocemos o cómo percibimos el mundo, mientras los segundos son una cuestión psicológica cuyas fuentes o causas son extremadamente variadas.

29 Podría incluso aludirse a estos diversos tipos de parcialidad con términos distintos como la neutralidad o la independencia. Sin embargo, en el discurso sobre la prueba pericial se usa fundamentalmente el término «imparcialidad». 
Por otro lado, es posible que los dos primeros tipos de parcialidad, a diferencia del tercero, dependan en un sentido más fuerte de la voluntad del perito; la parcialidad debida a sesgos cognitivos, en cambio, podría ser fácilmente remediable si el experto asumiera dicha falta y, por ejemplo, incorporara la información faltante a su análisis o reevaluara sus resultados en función de la falta de información. Aunque los tres tipos podrían estar relacionados, es importante diferenciar el tipo de parcialidad que está en juego, incluso porque los mecanismos procesales necesarios para abordar o controlar uno u otro tipo son muy diversos.

La jurisprudencia y la doctrina al tratar la imparcialidad del perito se suelen concentrar en la imparcialidad de origen, con lo que conceptualmente el perito nombrado por el juez es imparcial y el de parte es parcial en ese sentido. El perito nombrado por las partes sufre de una parcialidad de origen estructural, dado que si lo que aquél concluye no favorece a la parte que pretende introducirlo a juicio, ésta simplemente no lo presentará; a diferencia del perito seleccionado de alguna manera por el juez. Favorece a esto, además, que el cúmulo mayor o menor de operaciones periciales que los expertos seleccionados por las partes deban realizar a efectos de sus conclusiones (o afirmaciones testimoniales), son realizadas fuera del proceso y sin mayores controles judiciales.

Ahora bien, las circunstancias anteriores no necesariamente implican una parcialidad disposicional ni cognitiva del perito de parte. Si no distinguimos los distintos tipos de parcialidad, resultaría bastante difícil dar cuenta de los casos en que el peritaje ofrecido por un perito parcial de origen es correcto o los casos en los que un peritaje ofrecido por un perito imparcial de origen es incorrecto. Como parece evidente, los problemas de la prueba pericial son mucho más amplios que aquello que la imparcialidad de origen puede abarcar y/o resolver.

Diversos sistemas jurídicos han acudido a una especie de juramento del perito o de sanciones civiles, administrativas, penales, etc., como medida para proteger la imparcialidad pericial. ¿Qué parcialidad podrían cubrir? Las normas que regulan el perjurio o el falso testimonio pueden ser vistas como un incentivo para no mentir, pero en sí mismas no garantizan la verdad o la falsedad de la prueba pericial. Por ello, no se trata sólo de una discrepancia entre el dicho pericial y la verdad, sino que la idea de falsedad en juego implica un conocimiento de la verdad y la manipulación voluntaria o consciente y/o evitable de los datos. Incluso si aceptáramos que el juramento es una manifestación de «autocontrol del perito», éste podría estar diciendo lo que considera verdadero y, no obstante, estar equivocado ${ }^{30}$. Por ello, tanto el juramento como las sanciones por falso testimonio bien pueden ser reconstruidos como un mecanismo procesal tendente a evitar la parcialidad disposicional.

Más difícil de identificar y abordar es la parcialidad cognitiva que, algunas veces, podría no depender de la voluntad del perito o ni siquiera ser consciente de ella; pensemos, por ejemplo, en que el perito de parte a menudo realiza sus informes con base en la información que le provee quien le contrata y, por solo ese hecho, dicha infor-

30 Por supuesto, luego está el problema de determinar que el perito sabía la verdad que fue manipulada. Y también el de que formulara enunciados falsos pero evitara formular otros verdaderos que conocía y no expresó. 
mación puede ser sólo parte de toda la información relevante que el experto hubiese podido considerar o tener acceso a ella. Ahora bien, en mi opinión la mejor etapa para identificar este tipo de parcialidad no es la admisibilidad de la prueba sino su práctica, puesto que es entonces cuando el juez conoce mejor el caso y, sobretodo, cuando tiene posibilidad de cuestionar la completitud de las afirmaciones periciales, contrastar las pruebas disponibles, etc. Esto supone la práctica de la prueba mediante el principio de contradicción en su doble faceta, es decir, como herramienta de control de las partes y como herramienta cognoscitiva del juez. Lo que, a grandes rasgos, supone a su vez que el perito acuda a la audiencia respectiva a explicar (no sólo a ratificar o repetir oralmente su informe) y que tanto las partes como el propio juez puedan preguntar todo aquello que lleve a una mejor comprensión de las afirmaciones realizadas ${ }^{31}$.

Este epígrafe inició con ejemplos sobre cómo ha sido (muy positivamente) considerada la imparcialidad pericial en la valoración de este tipo de pruebas; sin embargo, podemos concluir que todos ellos presuponen una concepción demasiado tosca de la imparcialidad. Pues si bien la imparcialidad de origen es constitutiva del perito de confianza del juez y, por el contrario, el perito de parte sufre de una parcialidad de origen; finalmente, ambos tipos de peritos pueden aun ser parciales disposicional y cognitivamente, con independencia de su origen. Los jueces y tribunales deberían considerar sobretodo la imparcialidad cognitiva a efectos de atribuir valor probatorio a una prueba pericial y ejercer los mecanismos procesales dotados por el legislador para evitar la imparcialidad motivacional, mientras las partes siguen ejerciendo su derecho a elegir y presentar al perito que mejor les convenga (y ello sin tener como resultado que con independencia de cuán buen peritaje presenten siempre tenga un valor probatorio menor).

\section{CRITERIOS DE ADMISIBILIDAD PARA LA PRUEBA PERICIAL DE PARTE}

Las razones para hacer adiciones al criterio de relevancia a efectos de admitir una prueba podrían ser sumamente variadas; sin embargo, en términos generales podemos distinguir entre aquellas relacionadas con la averiguación de la verdad y aquellas relacionadas fundamentalmente con decisiones de política pública independientes de la averiguación de la verdad. Entre estas últimas, el ejemplo paradigmático lo constituye la exclusión de las llamadas pruebas ilícitas ${ }^{32}$. Ahora bien, si se defiende que uno de

31 No es lugar para ahondar en las dos facetas del principio de contradicción, sin embargo es necesario decir cuando éste es comúnmente considerado de forma exclusiva como una herramienta de control de las partes, tanto hacia la información presentada por su contraparte como hacia el razonamiento que hasta esa etapa realiza el juzgador. Que las partes se critiquen mutuamente sus elementos de juicio puede servir al juzgador para valorar mejor la calidad de dichas pruebas, aunque esto supone un escenario en el que se discuta seriamente el contenido y la calidad de las pruebas. Es decir, sólo si las partes realizan una adecuada práctica de las pruebas en contradicción entonces éste podrá desplegar sus funciones epistémicas. Pero, ¿qué pasa en aquellos casos en que las partes no realicen tal trabajo o, aun realizándolo, el juez no tiene la información que requiere? Es en la práctica de la prueba pericial donde el juez tiene la posibilidad de disipar cualquier duda sobre la información experta presentada por las partes o incluso desafiar él mismo las afirmaciones realizadas por el perito, y por ello el principio de contradicción como herramienta de control de las partes debe completarse con la faceta como herramienta cognoscitiva del juzgador de ese mismo principio.

32 Lo menciono sólo como ejemplo, pero debo advertir que nada diré sobre el criterio de licitud de las pruebas periciales de parte ni de ningún otro tipo de elementos de prueba, cuyo análisis sobrepasa los límites de este trabajo. 
los objetivos primordiales de un proceso judicial es la averiguación de la verdad, una discusión muy relevante es el costo que supone para ésta la exclusión de pruebas relevantes por razones no-epistémicas ${ }^{33}$, además de las discusiones sobre la eficacia de la exclusión para alcanzar los objetivos que se buscan con ello y/o si estos no pudiesen ser alcanzados mediante otros mecanismos menos costos para la averiguación de la verdad.

Pues bien, todas estas discusiones cobran suma importancia en el tema que nos ocupa, debiendo analizarse no sólo cuándo una prueba pericial ofrecida por alguna de las partes resulta relevante o irrelevante ${ }^{34}$, sino también las razones tanto epistémicas como no-epistémicas para regular y/o decidir la exclusión de pruebas periciales de parte relevantes. Así pues, podríamos tener razones para admitir o excluir una prueba pericial de parte atendiendo a la información experta que se presenta; al juzgador de los hechos; y al contexto en el que se toma la decisión ${ }^{35}$.

La fundamentación de los criterios adicionales será siempre relativa al contexto procesal de cada sistema y al diseño institucional de los aspectos probatorios del proceso en su globalidad. Sin embargo, quisiera añadir en este punto que, por mi parte, estimo que deberíamos partir de una regla pro-admisión que diga algo como «en caso de duda, ¡admita!». Así, por ejemplo, si el juez tiene dudas sobre la relevancia o irrelevancia de un elemento de juicio, entonces bajo esta regla, debería admitirla; o si, asumido que se requiriera valorar la fiabilidad de una prueba pericial de parte para su admisión, si el juez dudara sobre la fiabilidad o no-fiabilidad de ésta, entonces debiera admitirla ${ }^{36}$.

Con independencia de las razones que se tengan para decidir la admisión o la exclusión de una prueba pericial de parte, hay que tener en cuenta que estamos ante una decisión que:

a) No debería adelantar y/o confundirse con el juicio sobre la suficiencia probatoria, debiendo ser menos exigente que, por ejemplo, la atribución de valor probatorio o

\footnotetext{
Ahora bien, vale la pena matizar que una posible justificación de la exclusión de algunas pruebas ilícitas es de carácter epistemológico; pensemos en las pruebas obtenidas mediante tortura, evidentemente la calidad de éstas puede verse ampliamente cuestionada dada la situación de constreñimiento en que se encuentra el individuo y ello justifica en sí mismo su exclusión del proceso. Sobre esta línea de justificación de las pruebas ilícitas en Europa, más allá de las consideraciones de los diversos derechos nacionales, vale la pena seguir la doctrina jurisprudencial elaborada por el Tribunal Europeo de Derechos Humanos. Fundamentalmente las STEDH de 12 de julio de 1988 y de 11 de julio de 2006.

${ }_{33} \mathrm{Al}$ respecto es referencia obligada LAUDAN (2006).

34 Según Abel Lluch (2009: 167), «[1]a admisión a trámite de la demanda (o en su caso de la contestación de la demanda) comporta la incorporación de los dictámenes de parte a las actuaciones, pues no están sujetos a un juicio de pertinencia y utilidad como los restantes medios de prueba [...], y la única intervención que se prevé del juez [...] es el llamamiento de los peritos a juicio». En este sentido, no es de extrañar que después asegure que la pericial de parte «comporta una excesiva privatización de la prueba pericial» o que «reduce la intervención judicial más allá de sus justos límites» (ABEL LLUCH, 2009: 30-31). fluir.

${ }^{35}$ Las categorías de esta clasificación no son mutuamente excluyentes, de modo que bien podrían con-

36 En el mismo sentido, aunque hablando de todo tipo de elementos de juicio y no sólo de la prueba pericial de parte, vid. FERRER (2007: 69). En contra de esta regla general está THAYER (1898).

No desconozco que esta regla pro-admisión podría tener como consecuencia que los procesos judiciales sean más largos o más costosos, en cualquier caso la economía procesal será objeto de análisis de epígrafes posteriores en este trabajo.
} 
la toma de decisión sobre los hechos. Si se consideran criterios de admisión o exclusión en atención a la calidad de la información, habría que tener cuidado en no adelantar un juicio sobre la suficiencia probatoria, sobre todo en aquellos casos donde es un mismo juzgador el que decide sobre la admisión de las pruebas y sobre la valoración de las mismas. En general, debería aguardarse la valoración de la calidad de la información para la etapa de valoración propiamente dicha.

b) Se debe tomar considerando la información disponible en ese momento procesal. La cantidad y el tipo de información disponible puede variar, entre otras razones, dependiendo de cómo esté conformada la etapa correspondiente: no es lo mismo, por ejemplo, decidir sobre la admisibilidad de una prueba únicamente bajo un escrito de demanda más o menos completo justificando la utilidad de ésta que en una audiencia preliminar donde las partes deben argumentar (y contra-argumentar) de forma más extensa por qué una prueba debería ser admitida o no ${ }^{37}$.

c) Y, muy relacionada con los puntos anteriores, que convendría una decisión bolista y no monista considerando precisamente la etapa procesal en análisis y en función del resto de pruebas propuestas por las partes.

La discusión sobre la admisibilidad de una prueba pericial de parte está íntimamente vinculada con nuestras consideraciones respecto a si se está en un entorno adecuado para recibir testimonios que puedan conducir a la verdad y donde juegan también elementos sobre el adecuado funcionamiento del juez como receptor testimonial. Veamos.

\subsection{La información experta}

En términos muy generales, podría sostenerse que el derecho debería estar interesado sólo en determinado tipo de información que cumpla con ciertas características que se consideran indicios de su calidad. La idea subyacente sería que sólo tienen relevancia jurídica aquellos conocimientos expertos que gocen de las características $x \mathrm{o} z$. Esto podría conllevar la adopción de una actitud más conservadora respecto al tipo de información que se admitiría en sede jurisdiccional; sin embargo, esa decisión debería adoptarse a nivel legislativo y no ser dependiente de las decisiones judiciales en los casos particulares, sobre todo a efectos de respetar la seguridad jurídica ${ }^{38}$.

Supongamos que el legislativo español considerara la alternativa propuesta por NieVA (2009: 402), cuando afirma que:

[...] se hace patente la necesidad creciente de que la ley, o en su ausencia los Tribunales competentes, establezcan requisitos que, al aplicarse, excluyan [...] pruebas periciales que no observen los avances y planteamientos cientificos actuales ${ }^{39}$.

37 Evidentemente no es lo mismo si, por ejemplo, el perito presenta un informe por escrito para que las partes lo adjunten a su demanda que si éstas últimas sólo dan a conocer al juez su intención de llamar al perito $\mathrm{X}$ dado que consideran relevante introducir conocimiento experto al proceso. En este último caso, ¿qué evaluaría para admitir el testimonio si aún no se tiene un testimonio?

Caso muy distinto es si los sistemas prevén algo similar al preliminary hearing estadounidense.

${ }^{38}$ Una propuesta así es asumida por DuCE (2010: 80) cuando afirma que «[a]l sistema legal sólo le interesa escuchar la opinión experta en la medida que ella tenga un nivel de validez importante dentro de la comunidad de especialistas a la que pertenece». O de GOLD (2003: 25) «el sistema jurídico debería admitir como prueba pericial sólo aquello que la buena ciencia aceptaría como tal y nada menos que eso».

39 Las cursivas son mías. 
Por supuesto, a los tribunales les correspondería la (muy difícil) tarea de evaluar para su admisión si una prueba pericial satisface los requisitos legislativos, que en este ejemplo sería «observar los avances y planteamientos científicos actuales». Evidentemente el primer problema con el que se encontrarían sería su aplicabilidad a pruebas periciales no-científicas y cómo determinar tal cuestión ${ }^{40}$. Pero, la pregunta de fondo más interesante versa sobre el fundamento de dicho criterio, con el problema adicional de que las técnicas o métodos noveles parecieran ser casi por definición de baja o nula calidad ${ }^{41}$. Ahora bien, si la aceptación general o el adjetivo «novel» dependen de alguna forma del paso del tiempo, lo único que ese lapso podría llegar a asegurar es que tengamos mayor información sobre la técnica o el método en cuestión (REDMAYNE, 2001: 108).

$\mathrm{Y}$ es aquí donde en mi opinión reside el único criterio indispensable para la admisión de pruebas periciales de parte en atención a su calidad: que se tenga información precisamente sobre la calidad de éstas. Podría decirse entonces que el único criterio indiscutible respecto al tipo de información que se admite es que se trate de información empírica susceptible de arrojar datos sobre su calidad. Conviene advertir que no se trata tanto de una evaluación sobre la calidad de la información misma, sino acerca de la posibilidad de formarse un juicio sobre la calidad de la información, cuyos indicadores no se agotan en las meras credenciales de los expertos. Si, en definitiva, no tenemos ninguna información sobre la calidad de la astrología o la lectura de los posos del café, en ningún caso podríamos considerar que fundar una decisión en la información aportada por ese tipo de «pericias» haría aumentar las posibilidades de acierto en la decisión y, por ende, deberían ser inadmitidas.

Hay que recordar que la decisión sobre la admisibilidad de un elemento de prueba es categórica (o se admite o se excluye), por lo que el criterio o los criterios utilizables para adoptar esa decisión deberían ser también, en principio, categóricos. Si, en cambio, los criterios que se plantean son graduales, entonces se requerirá además una especie de estándar de admisibilidad que especifique a partir de qué grado de cumplimiento de éstos se debe optar por la admisión de la prueba en cuestión y por debajo de qué grado se debe decretar su exclusión.

Vale la pena plantear un punto más sobre la calidad de la información que se presenta como prueba pericial ahora en relación con los llamados «hechos notorios» ${ }^{42}$.

40 Una pregunta fundamental es ¿cómo el juez obtendría información sobre la aceptación de la comunidad científica?, ¿mediante otro testimonio experto? Y si es así, entonces, tendríamos otra vez los mismos problemas sobre cómo el juez se allega de conocimiento experto, la valoración de su calidad, etcétera.

NIEVA (2009: 412), por ejemplo, identificándolos como unos «sencillos principios generales» habla sobre si las técnicas o teorías científicas han sido aplicadas previamente; si han sido publicadas en revistas reconocidas y de uso regular en la práctica; el grado o nivel de error y variabilidad e incertidumbre de los datos; su aplicación según los estándares y normas de calidad vigentes; y, no podía faltar, que sean generalmente aceptadas por la comunidad científica. Sólo que en este último caso insiste en que sea la comunidad internacional.

41 Duce (2010: 49), por ejemplo, considera que la opinión emanada de la ciencia novel o en estado de desarrollo o consolidación no ha sido admitida como válida por la comunidad científica y que por ello tiene poco valor probatorio. En mi opinión, un estándar de prueba científico es distinto a un estándar de prueba jurídico, por lo que las determinaciones realizadas en un ámbito distinto al jurídico no tienen por qué ser adoptadas sin más.

42 Sobre los hechos notorios, puede verse STEIN (1893) y CALAMANDREI (1945), entre otros muchos. Para STEIN (1893: 141), «[e]xiste la notoriedad fuera del proceso cuando los hechos son tan generalizadamente 
Si acudimos a MCCORMicK (1954: 363 ) encontraremos que al hablar de uno de los criterios de admisión de pruebas periciales más conocidos en el ámbito anglosajón, como es la aceptación general de la comunidad científica, él lo analiza como un criterio adecuado para que los tribunales tomen un hecho como judicial notice ${ }^{43}$, más no para evaluar la admisibilidad de un elemento de prueba. Parece que el argumento subyacente es que se tienen garantías muy fuertes de la calidad o la verdad de cierta información que podrían llevar al juez a tomarlas como hechos notorios y no como un elemento de prueba más ${ }^{44}$.

Más allá de advertir que habitualmente los hechos notorios son definidos como hechos conocidos por la generalidad de la comunidad social a la que el juzgador pertenece, y que MCCORMICK cambia la referencia de esa comunidad social a la comunidad científica $^{45}$ (lo que puede resultar jurídicamente problemático), cabría preguntarse si los llamados hechos notorios pueden estar constituidos por conocimientos considerados como expertos. Es decir, ¿un hecho que es conocido de forma notoria como verdadero, dados su sólidos fundamentos sostenidos en un largo lapso de tiempo, puede seguir siendo conocimiento experto?, ¿la teoría de la gravedad, al menos en su versión más superficial, es conocimiento experto? Si la respuesta es negativa entonces se generaría una peculiar situación: entre más conocida sea la calidad de ciertos conocimientos originalmente expertos entonces menos expertos parecieran ser.

Dejando de lado este pequeño apunte sobre los hechos notorios, una última estrategia que me interesa abordar aquí, relacionada con la admisibilidad de pruebas periciales de parte en atención a la calidad de la información, es la llamada admisión asimétrica. En términos generales, se trata de una estrategia de distribución del riesgo del error entre las partes consistente en ser menos exigente con una de ellas (típicamente el acusado en materia penal) y/o más exigente con la otra (si seguimos en materia penal, con la acusación); desde luego, beneficiando a una de las partes ${ }^{46}$.

percibidos o divulgados sin refutación con una generalidad tal que un hombre razonable y con experiencia de la vida puede declararse [...] convencido de ellos [...] . El conocimiento no está aquí articulado internamente de modo distinto al conocimiento individual del testigo, sino sólo en relación al número de cognoscentes». Las generalizaciones en las que se basa STEIN para dar cuenta de los hechos notorios pueden llegar a ser bastante problemáticas dado que puede cuestionarse su corrección. Al respecto, puede consultarse ANDERSON, SCHUM y TWINING (2005: 265 y ss.), quienes, además, distinguen entre las generalizaciones de sentido común o de conocimientos del ciudadano de nivel medio y los hechos notorios, vid. nota 66 .

43 Respecto este tema, puede consultarse, entre muchos otros, ANDERSON, SCHUm y TwINING (2005: 273), quienes advierten que no se debe confundir la judicial notice con las «generalizaciones del sentido común», dado que se puede tratar de hechos específicos (como que Lima es la capital de Perú), no necesariamente generalizaciones, y, además, que la corrección de eso que identificamos como sentido común puede ser cuestionada.

44 También llama la atención sobre esta cuestión PÉREZ GIL (2010: 108). Aunque, en mi opinión, introduce un problema al afirmar que «si bastase una mera consulta de fuentes de información fácilmente accesibles (un libro básico, internet, etc.), algo que ni siquiera merecerá en su momento ser explicitado en el fallo» entonces cabría referirse a un hecho notorio. En mi opinión, el problema es claramente explicitado si acudimos a la FRE 201 (b-2), que habla sobre la judicial notice como hechos susceptibles de determinar correcta y rápidamente acudiendo a fuentes cuya corrección no pueda ser razonablemente cuestionada.

45 Por cierto, el problema de un criterio como este pasa por atender a los fundamentos de dicha aceptación, es decir, por qué es aceptado por la comunidad, más allá del sólo hecho de que es aceptado por una comunidad.

46 Hay al menos dos estrategias para la distribución del riesgo del error en un proceso judicial: una es que éste esté totalmente contenido en los estándares de prueba (LAUDAN, 2006) y otra es que se establezcan diversas reglas en las distintas etapas probatorias que vayan distribuyendo ese riesgo (STEIN, 2005). Algunos autores consideran que la segunda opción es la más adecuada dada la imposibilidad de formular estándares de prueba 
Por lo que hace a la calidad de las pruebas periciales, esta estrategia supondría entonces que a la parte beneficiada se le admitan este tipo de pruebas aun cuando sean de baja calidad y/o se exija a la otra parte que presente pruebas periciales de mayor calidad. Así, por ejemplo, EDMOND y MERCER (2002: 58), en el ámbito concreto de la prueba pericial, consideran que el derecho al debido proceso implica que se valore la calidad de las pruebas incriminatorias en la etapa de admisión para compensar las deficiencias en la valoración del conjunto de pruebas ${ }^{47}$. Al respecto, vale la pena comentar dos cuestiones.

El punto de partida es la consideración de que la admisión de la prueba pericial debe estar condicionada no sólo por su relevancia sino también por la calidad de la prueba misma. Pero a diferencia de algunos de los argumentos antes analizados, no se trata de un argumento epistémico, es decir, no hay un interés genuino en la calidad de la información presentada sino una decisión política para distribuir el error de modo favorable para el acusado. Antes de aludir a la distribución del error, enfatizo una vez más que, en mi opinión, la calidad de las pruebas debería ser una cuestión a considerar fundamentalmente en la etapa de valoración y no algo que determine la admisión.

Ahora bien, aun si aceptáramos que ya en la admisión de pruebas periciales de parte debe hacerse un control de la calidad de éstas, vale la pena recordar que en el proceso judicial estamos interesados no sólo en distribuir el riesgo del error sino también en minimizar las posibilidades del error. Y, precisamente, creo que cualquier valoración de la calidad de la información debería atender a la disminución del error y no a su distribución, suponiendo claramente que las pruebas de mayor calidad aumentan la probabilidad de llegar a decisiones correctas. Así pues, si se controla la calidad de las pruebas para su admisión debería entonces hacerse de forma simétrica; lo contrario es una estrategia que incluso podría dar lugar a consecuencias absurdas, pues con cierta probabilidad, ella misma podría ser la fuente del error que luego pretende distribuir, i. e., crearía el error para luego distribuirlo ${ }^{48}$.

Llegados a este punto es menester insistir entonces en que la calidad de las pruebas periciales de parte es el objetivo de la valoración que realiza el juez a efectos de otorgarle valor probatorio y una vez que ha sido sometida a contradicción durante su práctica (donde seguramente se podrán obtener más datos sobre su calidad). Por

precisos (BAYÓN, 2008); sin embargo, la segunda opción presenta también el grave problema de controlar cuánto beneficio de la duda su otorga a las partes a través de las distintas reglas probatorias.

BAYÓN (2008: 20) sostiene que, al menos en algunos casos, una serie de normas sobre la admisibilidad y la valoración de la prueba en conjunto y a largo plazo generarían un número total de errores menor que el que produciría el funcionamiento de un sistema presidido por los principios de admisibilidad de toda prueba relevante y de libre valoración. No pretendo aquí discutir el argumento de BAYÓN, sino simplemente apuntar algunos argumentos sobre por qué la admisibilidad de una prueba pericial de parte no debería formar parte de ese conjunto del que habla BAYÓN.

47 También ReDmayne (2001: 112), por ejemplo, afirma que la competencia epistémica del jurado es una cuestión irrelevante para la admisibilidad de pruebas pues lo que debería importar, según él, es el riesgo de error.

Otras reglas de admisión/exclusión que favorecen la asimetría son, por ejemplo, aquellas que establecen la exclusión de pruebas «more prejudicial than probative» o que pudiesen llegar a causar un «unfair prejudice», dado que ambas son generalmente aplicables sólo a las pruebas presentadas por la acusación.

48 En el mismo sentido Allen y NAFISI (2010: 145) afirman que relajar los estándares de admisibilidad de las pruebas solo incrementaría el riesgo del error. «Asegurar la paridad de los errores [...] podría ser justo, pero sin duda se haría a costo de la corrección en la determinación de los hechos». 
ello, la preocupación en torno a la calidad de la información experta contenida en una prueba pericial a efectos de decidir su admisión o exclusión debe ser la posibilidad de tener información precisamente sobre dicha calidad.

Una vez dicho lo anterior, pasemos ahora a analizar si ciertas características del sujeto que valora la prueba pericial deben ser consideradas para previamente decidir la admisión de ésta.

\subsection{Las necesidades del juez}

Antes hemos visto la desconfianza en las capacidades cognitivas del juzgador como línea argumentativa para admitir o excluir una prueba pericial de parte, corresponde analizar ahora otro posible criterio que gira también en torno a la situación epistémica del juzgador, pero esta vez sobre sus necesidades y no sobre sus capacidades. Y es que algunos ordenamientos establecen como criterio adicional a la relevancia la necesidad de la prueba pericial en cuestión; y parte de la jurisprudencia y la doctrina la han interpretado como una necesidad epistémica de un juzgador concreto respecto de los conocimientos expertos que se supone suministraría una prueba pericial. Un buen ejemplo de esto lo constituye la siguiente sentencia del Tribunal Supremo español:

[...] el Juez puede sustituir al perito cuando se considere suficientemente informado por sí según su preparación para conocer y apreciar el objeto o la cuestión litigiosa que hubiera necesitado la intervención de otra persona que tenga los conocimientos científicos, artísticos o prácticos requeridos por las circunstancias del caso ${ }^{49}$.

Entiéndase bien, no se refiere a la necesidad de la información dada la cuestión a resolver ${ }^{50}$, sino a la necesidad de la información según el agente concreto que va a resolver. Aquí la locución «según el agente» significa tanto que la evaluación giraría en torno a sus propios estados mentales, como que le correspondería hacer la (auto) valoración respectiva. Hago referencia a los estados mentales porque dicha necesidad podría entenderse como:

a) el juez cree que la necesita, es decir, cree que no tiene los conocimientos (o las habilidades para conocer); o,

b) el juez la necesita, es decir, realmente no tiene los conocimientos (o las habilidades para conocer).

La formación de la creencia del juez supondría una especie de autoevaluación de su nivel cultural y, por supuesto, la vinculación de la admisibilidad a creencias subjetivas que convertirían en irrecurribles las decisiones sobre la admisión, pues ¿cómo se podría objetar que un juzgador necesitaba, o no, la pericia para decidir el caso si depende únicamente de sus creencias?

El hecho de que el juez realmente la necesite es subjetivo en un sentido más débil, aunque también bastante problemático; pues si bien es cierto que no vincula la admi-

49 STS, Sala $1 .^{\text {a }}$, de 10 de febrero de 1994, FJ 4. ${ }^{\circ}$ (RJ 1994/848).

50 Lo que hace suponer una diferencia con el criterio de relevancia y también con el criterio de la redundancia. 
sibilidad con las creencias del juez, sí la vincula a un sujeto concreto y esto conlleva serios problemas. Más allá de advertir que bajo esta perspectiva evidentemente un cambio de juzgador podría cambiar radicalmente la valoración sobre la necesidad de un experto presentado por las partes ${ }^{51}$, cabría preguntarse por qué las necesidades epistémicas de un juzgador serían importantes para admitir una prueba pericial ofrecida por las partes. Cuando se trata de un perito ofrecido por las partes parece extraño decir que el objetivo es satisfacer las necesidades del juez y no sólo ofrecerle información relevante a ser incorporada en su razonamiento; las partes, cuando presentan la demanda o la denuncia, ignoraran qué juzgador conocerá de su caso e, incluso sabiéndolo, no tendrían por qué conocer sus necesidades epistémicas generales y menos aún aquéllas relevantes para el caso concreto.

Además, conviene recordar lo dicho anteriormente respecto a que el conocimiento experto ofrecido por las partes en un proceso sufre de un «parcialidad estructural». Así, dado que éstas presentarán únicamente al experto que, por la razón o motivo que sea, sustente una afirmación que sea favorable a su hipótesis sobre los hechos, es posible prever que las distintas partes presenten peritajes contradictorios, con lo que cabría la posibilidad de que las necesidades epistémicas del juez se ampliaran precisamente por la presencia de éstos.

Por todo esto, en mi opinión, condicionar la admisión de una prueba pericial presentada por las partes a las necesidades cognitivas de un juzgador resulta insostenible. En cambio, hay otra forma más prometedora de interpretar dichas necesidades epistémicas y que pasa por relacionarlas con la actividad o la función de los jueces, no de un juez concreto, en materia de valoración de las pruebas (tanto en lo individual como en conjunto). Y es que cualquier inferencia sobre la verdad o la falsedad de los hechos debe ser realizada por el juzgador, y no por un perito; por ello, debe inadmitirse una prueba pericial sobre la credibilidad de un testigo que luego concluye, por ejemplo, que lo dicho por el testigo es verdadero (o falso) ${ }^{52}$.

De cualquier manera, vale la pena enfatizar que en este (reducido) tipo de casos es donde tiene total sentido hablar de una usurpación de las funciones del juzgador por parte de un perito, donde sí que puede haber una fuerte tensión entre el conocimiento del juzgador y aquellos que le serían proporcionados por un perito y/o entre la función del juez y la función del perito. Y no, como se suele plantear el peligro de usurpación de funciones, de todo tipo de pruebas periciales.

Por supuesto, una prueba pericial sobre la credibilidad de un testigo puede constituir una muy relevante prueba sobre la prueba que brinde información adecuada a los

51 Advierten sobre esto Montero Aroca (1998: 182), Picó i Junoy (2001: 48) y Abel LluCH (2012: 659), entre muchos otros procesalistas españoles.

52 En la literatura anglosajona es conocida como la ultimate issue rule, que es definida como una cuestión litigiosa que es suficiente, por sí misma o junto con otras, para resolver el caso (GARNER, 2009: 908). Por su parte, ROBERTS y ZUCKERMAN (2004: 310) lo consideran como el criterio esencial de la admisibilidad, al menos en el Reino Unido.

Una reciente sentencia del Tribunal Supremo español (648/2010) se ha pronunciado al respecto afirmando que: «[c] onvertir el dictamen de los peritos psicológicos, singularmente lo que éstos denominan conclusión psicológica de certeza, en un presupuesto valorativo sine que non, llamado a reforzar la congruencia del juicio de autoría, supone convertir al perito en una suerte de pseudoponente, con una insólita capacidad para valorar anticipadamente la credibilidad de una fuente de prueba». 
juzgadores para realizar el tipo de inferencias que se les pide. Por ejemplo, si un testigo afirma que vio a la parte acusada arrastrando el cadáver de la víctima que en vida pesaba, supongamos, 120 kilos, siendo la acusada una mujer menuda, una prueba pericial podría demostrar su incapacidad para cargar ese peso; o si el testigo tiene una visión defectuosa y afirma haber visto los hechos del caso en una noche oscura, sus afirmaciones pueden ser ampliamente cuestionadas mediante una prueba pericial realizada por un oculista, debido precisamente a la (in)capacidad de visión del testigo. Entonces el juez podría inferir a partir de las pruebas periciales que demuestren la no-credibilidad del testigo, suponiendo que éstas están debidamente fundadas, que las afirmaciones testimoniales son falsas.

Por otro lado, y para finalizar los argumentos que se plantean respecto la admisión o la exclusión de una prueba pericial de parte relevante atendiendo a la situación epistémica del juzgador de los hechos, toca analizar un novedoso argumento desarrollado por NANCE (2004: 230), que no se funda en las capacidades cognitivas del juzgador ni en sus necesidades epistémicas, sino en la administración de sus recursos cognitivos. En términos generales, consistiría en incentivar que el juzgador en un caso concreto dedique sus recursos cognitivos a las pruebas periciales de mayor calidad, excluyendo las pruebas periciales de menor calidad.

El argumento presentado por NANCE implica necesariamente una evaluación comparativa entre las pruebas presentadas por cualquiera de las partes ${ }^{53}$ y sólo en aquellos casos en que dichas pruebas aborden la misma cuestión. Entiéndase bien, no se está diciendo que se excluyan las pruebas de la contraparte dada la calidad de las pruebas de la otra parte, sino que se atienda al conjunto de pruebas presentado por cada una de las partes. Así pues, para NANCE, habría que excluir una prueba pericial presentada por JF cuando el mismo JF haya presentado otra prueba (también) pericial pero de mayor calidad.

El presupuesto que subyace a este argumento es que, en algunas circunstancias, «menos información es mejor cognitivamente» ${ }^{54}$, en contra de la tesis común que sostiene que disponer de más información relevante es siempre mejor. Según GIGERENZER (2006: 21), «en la mayoría de los modelos de racionalidad se da por hecho que la calidad de la decisión siempre incrementa —o al menos no disminuye- cuando incrementa la cantidad de información». Si relacionamos esto con la conformación del conjunto de elementos de juicio en la etapa de admisión probatoria que ahora analizamos y partimos de que la admisión probatoria tiene como objetivo la conformación de un conjunto de elementos de juicio lo más rico posible, tendríamos que diferenciar entre un conjunto rico cuantitativamente y cualitativamente. Aquí, «cualitativamente» no sólo hace referencia a la diversidad de tipos de pruebas, sino a que cada uno de esos tipos de pruebas sean de cierta calidad; calidad que interesaría a efectos de que

53 Debe enfatizarse que se trata de una decisión de carácter eminentemente comparativo que implica que uno de los elementos sea de una calidad lo suficientemente mayor para excluir a otro elemento; o, mejor aún, si es el caso de varias periciales, que el conjunto de las periciales sea igualmente bueno al excluir uno de los elementos que la conforman (NANCE, 2004: 232). Por supuesto, si la parte sólo ha presentado una prueba pericial, bajo el esquema de NANCE, no tendría sentido entrar a analizar la posibilidad de excluirla con este argumento pues se terminaría en realidad adelantando la valoración de ésta.

54 Un argumento similar, identificado como peligro de desborde o sobrecarga de la información, pero analizando la admisibilidad de cualquier elemento de prueba, ha sido sugerido por FERRER BELTRÁN (2007: 85). 
el juzgador de los hechos administre adecuadamente sus recursos cognitivos. Por ello, sería adecuado seleccionar aquel elemento que concentrará la atención de éste, aunque tal vez no sólo de éste sino incluso de las mismas partes.

Hay que señalar que este argumento no necesariamente tiene que ver con un ahorro de tiempo, dado que posiblemente el tiempo que se pueda ahorrar en la etapa de valoración se deba invertir previamente en decidir la admisión o la exclusión de un elemento de prueba bajo este argumento. Ahora bien, la racionalidad de una estrategia heurística como ésta depende fundamentalmente del contexto particular en que se toma la decisión ${ }^{55}$, por lo que no es una estrategia adecuada o inadecuada en sí misma (GIGERENZER, 2006: 17).

Después de desarrollar el argumento en comento, NANCE (2004: 233) termina considerando que este tipo de criterio de admisibilidad sobre la calidad de un elemento de prueba no es el más adecuado. Aunque no lo dice explícitamente, parece que su objeción radica en que sea visto como la única forma de interpretar la tarea de gatekeeper exigida a los jueces en el contexto estadounidense a partir del caso Daubert y, más precisamente, pensando en un contexto perteneciente a la tradición del common law, donde el juez que decide la admisión debería ponerse en el lugar del jurado qua juzgador de los hechos para hacer las evaluaciones pertinentes a efectos de administrar los recursos cognitivos de éste. Pero, cabría preguntarse: ¿cuál sería la situación en sistemas de derecho romano-germánico?

Suponiendo que el mismo juez que decide la admisión valorará también las pruebas periciales presentadas por la parte correspondiente, como suele suceder en nuestros sistemas, podría ser mucho menos problemática la gestión de recursos cognitivos por el mismo agente, de modo que evite el desborde de información, considerando la que hasta ese momento ya tiene. También abona a esta cuestión el hecho de que el juez pudiera pedir, en etapas posteriores a la admisión, otras pruebas que en una situación distinta a la anterior pudiera considerar relevantes para la decisión. Así pues, en mi opinión, las diversas facultades probatorias de que gozan los jueces de tradición romano-germánica podrían favorecer la gestión de sus recursos cognitivos.

Con todo lo dicho hasta aquí sobre los diversos argumentos en torno a los decisores a efectos de controlar la admisibilidad de pruebas periciales, a manera de cierre, podría decirse que las capacidades de los jueces (o el ejercicio de éstas) son relevantes para los casos concretos que están decidiendo; si el tipo de prueba pericial concreta

55 Resulta claro que todo el argumento hasta ahora desarrollado pende de cuestiones heurísticas. Según GigerENZER (2006: 17) hay dos formas de analizar el carácter de la heurística: como solución a un problema (o forma de solucionar un problema) dadas las características de éste y como un problema en sí mismo dado que suele verse como una segunda mejor opción dada las limitaciones cognitivas de un sujeto. Si se asume la segunda versión, se asume también que las personas usan estrategias heurísticas sólo porque tienen capacidades cognitivas limitadas. Una concepción de este tipo puede ser encontrada en TVERSKY y KAHNEMAN (1982) y KAHNEMAN (2011).

Por supuesto, también está implícita la discusión sobre qué consideración merecen las limitaciones cognitivas. Así, mientras para algunos suelen ser fuente de ilusiones cognitivas o sesgos; para otros, podrían de hecho facilitar las funciones cognitivas, no sólo constreñirlas. En el primer sentido, un buen ejemplo es BuGLIOLI y ORTúN (2001: 21): «[1] os datos de la psicología apoyan la idea de que las capacidades humanas son limitadas y que las decisiones pueden tener sesgos cuando las actividades que se desarrollan son complejas o la información disponible tiene carácter probabilístico». 
presentada por alguna de las partes interfiere directamente con las funciones atribuidas a los jueces entonces se justifica su exclusión en el caso; y, finalmente, el juzgador puede excluir pruebas periciales presentadas por una parte si esta misma ha presentado otras pruebas periciales que en ese momento procesal pueden considerarse de mejor calidad, esto con el objetivo que el juez administre de mejor manera sus recursos cognitivos. Pasemos ahora a ver otro tipo de razones que pueden plantearse para limitar la admisibilidad de pruebas periciales de parte.

\subsection{El contexto procesal}

Como afirman Buglioli y ORTÚN (2001: 26), «el entorno institucional y organizativo puede limitar la racionalidad de las decisiones». Se entiende por entorno institucional el conjunto de restricciones formales e informales que regulan la interacción en ese contexto; y por entorno organizativo la forma de distribución de las facultades de decisión, de evaluar comportamientos e incentivar individuos. Atendiendo a estos entornos a efectos de discutir la admisión o exclusión de pruebas periciales de parte por razones relacionadas con el contexto jurisdiccional, podríamos encontrar al menos dos grandes líneas argumentativas:

a) La economía procesal como una restricción institucional ${ }^{56}$.

b) El control de las partes como una facultad organizativa del juez.

En comparación con otros criterios para fundar la admisión o exclusión de una prueba pericial de parte, estas líneas argumentativas no están fundadas en una preocupación por las capacidades cognitivas de los juzgadores o por la información experta que se ha ofrecido, sino más bien en ciertos contrapesos a considerar en el contexto procesal. Y a efectos de la admisibilidad de pruebas hay una diferencia importante entre los dos tipos de argumentos, mientras la economía procesal inclinaría la balanza hacia la exclusión de pruebas, el control de las partes tiene como objetivo la inclusión de pruebas pero de mayor calidad.

Dicho esto, iniciemos con el análisis del llamado principio de economía procesal, acotándolo evidentemente a la admisibilidad de las pruebas periciales de parte ${ }^{57}$. Asumo que la economía procesal es el ahorro de actividades procesales que conlleva una

56 Para entender mejor este punto, habría que relacionar al proceso judicial con su «publicización» o «socialización» que orienta el reparto de funciones entre el juez y los litigantes, indicando que «si bien los litigantes son libres de disponer de los intereses deducidos en juicio, o sea del objeto del proceso, no lo son respecto del proceso mismo, es decir, de su desarrollo, al concebirse no sólo como instrumento dirigido a la tutela jurisdiccional de derechos privados, sino además como función pública del Estado, interesado, por tanto, en el mejor cumplimiento de esa función» (PICÓ I JunOY, 2007: 103).

57 Para un amplísimo análisis sobre la economía procesal en general, vid. Comoglio (1980). Y para un análisis económico del derecho probatorio, $c f r$. POSNER (1999). Este último, aunque dedica algunas páginas a sistemas de tradición romano-germánica, está especialmente referido al derecho estadounidense; sin embargo, varias de las cuestiones ahí planteadas son fácilmente trasladables a nuestros sistemas.

STEIN (2005: 136 y ss.), por su parte, desarrolla algunas cuestiones críticas sobre un argumento costo-eficacia respecto la reducción de errores en materia penal mediante el uso de los diversos mecanismos que controlan la actividad probatoria. Habla entonces de la reducción máxima de las pérdidas sociales representadas por la suma de dos costos: el costo de los errores en la averiguación de la verdad y el costo de los procedimientos de averiguación de los hechos que reducirían dichos errores. 
disminución en el tiempo y/o los recursos materiales empleados en un proceso judicial $^{58}$. No vale cualquier disminución, sino una que observe cierta relación de proporcionalidad entre los medios y los fines del proceso judicial. Si partimos del presupuesto que la finalidad de la prueba en el proceso es la averiguación de la verdad, entonces la economía procesal en materia probatoria se circunscribirá a los posibles ahorros en la actividad probatoria que no socaven la averiguación de la verdad. Y, por ello, un argumento de economía procesal no debería tener efectos adversos para la averiguación de la verdad.

Al respecto, podríamos hacer una comparación con la exclusión de las pruebas relevantes pero ilícitas, que no se hace por razones epistémicas y, sin embargo, tiene efectos contra-epistemológicos; la exclusión de pruebas relevantes por cuestiones de economía procesal, por su parte, tampoco se lleva a cabo por razones epistémicas (sino por ahorro de tiempo y/o recursos) pero no debe tener efectos contra-epistemológicos.

En todo caso, dicho ahorro de actividades procesales puede plantearse desde dos perspectivas: como una directiva programática de codificación dirigida al legislador ${ }^{59}$ y como un criterio orientativo de las facultades discrecionales del juzgador dirigido precisamente a éste (COMOGLIO, 1980: 46). Sobre la primera, por ejemplo, en la discusión sobre la admisibilidad de la prueba pericial de parte, legislativamente a veces se limita el número de pericias que las partes pueden presentar sobre una misma cuestión. Sin embargo, esto tiene el problema de que en ocasiones la prueba de un hecho aconseja la adquisición de información proveniente de distintas áreas de conocimiento, en cuyo caso parece razonable disponer en el proceso de diversos peritos. Así pues, si no se quieren causar efectos epistémicos desfavorables debería descartarse una regla general que limite el número de peritos y más bien pudiera asumirse como criterio orientativo para el juez en función de las circunstancias del caso.

Por otro lado, la economía procesal como criterio orientador del juez consistiría en el propio juicio del juzgador sobre la utilidad de las actividades procesales en el contexto de un proceso judicial concreto a efectos de su toma de decisión fáctica ${ }^{60}$. Se trataría entonces de un criterio que oriente las decisiones del juez en materia de admisión de pruebas periciales en aquellos espacios donde cabe la discrecionalidad de éste. Y, sólo a efectos de ejemplificar esta posibilidad, podríamos pensar en dos casos:

58 Si seguimos la doctrina alemana citada por COMOGLIO (1980: 7), podemos distinguir un aspecto principal y un aspecto colateral de la economía procesal. El aspecto principal sería el ahorro tanto como sea posible de la actividad procesal de las partes o del juzgador que tendría como consecuencia, y aquí viene el aspecto colateral, un ahorro individual o colectivo de tiempo y especie.

También vale la pena notar que una decisión fundada en argumentos de economía procesal puede repercutir en otros procesos o incluso generar otras instancias para la revisión de esa decisión que ha inducido a un error al excluir el elemento de prueba en comento, etcétera.

59 POSNER (1999: 2), por ejemplo, asegura que «la estructura institucional y doctrinal del derecho probatorio estadounidense tiene una sutil lógica económica, aunque intuitiva, implícita e incompleta».

60 Entendido de esta manera, valdría la pena especificar que lo visto en párrafos anteriores sobre la administración de los recursos cognitivos del juzgador, hecha por el propio juzgador, podría ser vista como una especie de éste criterio, pues potencialmente podrían ahorrarse actividades procesales que conllevaran una disminución en tiempo y recursos materiales. Sin embargo, al no tener necesariamente tal resultado, vale la pena diferenciarlo. 
a) El supuesto en el que la prueba pericial de parte sea una prueba superflua en un conjunto, en principio suficiente, de pruebas no-periciales.

b) El supuesto en que el valor probatorio que parece pudiese tener un elemento de juicio no compense el gasto de tiempo y recursos.

La idea subyacente es que las pruebas periciales son de hecho costosas, por lo que si hay pruebas de otro tipo que resulten suficientes para acreditar los hechos o, bien, el valor probatorio de éstas se considera menor en comparación con sus costos, entonces habría que excluirlas en aras precisamente de evitar los costes que supone y, a la vez, que ello no represente un perjuicio a la averiguación de la verdad. El efecto de pruebas relevantes adicionales en la resolución de un caso tiende a disminuir, sin una necesaria disminución en los costos que éstas pueden producir (POSNER, 1999: 7 y 59).

Relacionado con este tipo de criterios, DucE (2010: 67), por ejemplo, afirma que siempre sería preferible introducir la información respectiva por otros medios de prueba y no mediante una prueba pericial que resulte adicional. Sin embargo, aunque en innumerables ocasiones hace referencia al aprovechamiento racional de los recursos ${ }^{61}$, DuCE termina estando más preocupado de las (dis)capacidades cognitivas del juzgador. En cualquier caso, la consecuencia de una concepción así es que en los casos en que se admitiese una prueba pericial se esperaría que tuviera un fuerte peso probatorio; en ese escenario posiblemente muchos casos en los que se presentasen este tipo de elementos probatorios serían determinantes para la toma de decisión. Y, quizá precisamente por ello, habría de ser más exigentes con los parámetros empleados por el juzgador.

Aunque es claro que desde el punto de vista económico los costos del peritaje de parte son asumidos por la parte y el juzgador no tendría por qué interferir en la decisión sobre su conveniencia, existen también otro tipo de recursos, como el coste económico del tiempo, el coste para la otra parte de contradecir el peritaje y, el ya analizado coste en los recursos cognitivos del juez, que podrían ser tomados en cuenta para la admisión de una prueba pericial. Sin embargo, me parece excesivo establecer una regla general como la sugerida por DUCE; además, seguro hay pruebas periciales menos costosas que otro tipo de pruebas, y, por ello, creo que la economía procesal es un argumento que sólo puede considerarse en el caso a caso. A ello hay que añadir también una cuestión más relacionada con la calidad del conjunto de elementos probatorios y es que ésta no sólo es cuantitativa (entre más pruebas mejor) sino también cualitativa (entre más pruebas de distintos tipos mejor).

El siguiente aspecto relevante a considerar para la admisibilidad de la prueba pericial de parte atendiendo al contexto en que se adopta la decisión tiene que ver con el entorno organizativo y, en particular, con el control de las partes (y sus abogados)

61 Por ejemplo, afirma que «el punto de la preocupación no es el uso de la prueba pericial en sí, sino más bien que un uso irracional de la misma, es decir, fuera de los casos en lo que se justifica, no es una cuestión neutra desde el punto de vista de los recursos, siempre limitados, con los que cuenta el sistema» (DuCE, 2010: 52). Pero, en cambio, pone más énfasis en lo que denomina «aporte probatorio versus prejuicio en el juzgador» y «valor probatorio versus influencia indebida en el juzgador». Cuya diferencia, según el propio autor, radicaría en que en el primer caso el prejuicio va en contra del acusado, mientras que en el segundo lleva a valorar equivocadamente al elemento de juicio. En mi opinión, esa diferencia no está justificada, dado que tanto el prejuicio como la influencia indebida pueden resultar en perjuicio del acusado. 
que podría hacer el juez en la etapa de admisión probatoria cuando se trata de pruebas periciales de parte.

Y aquí vale la pena detenerse en otra de las propuestas de NANCE (2004: 236 y ss.) para regular la admisibilidad de pruebas periciales de parte en sistemas adversariales como el estadounidense: el «principio de la mejor prueba disponible» ${ }^{62}$. La idea principal es que se utilice la exclusión de elementos de prueba para fomentar la presentación de mejores pruebas, pruebas con mayor valor probatorio y menos costosas para el juzgador o que logren un mejor balance entre estas dos cuestiones. Se trata, por supuesto, de ser más exigentes con la parte (cualquiera que ésta sea) que ha producido un testimonio pericial y que pretende que sea considerado en un proceso judicial; $y$, a la vez, incentivar que los tribunales sean consumidores más exigentes de conocimiento experto. Por ello podría verse como una estrategia cuyo objetivo es incrementar la calidad de las pruebas periciales que serán presentadas en los procesos judiciales.

Según NANCE (2004: 238), hay que tomar en consideración dos condiciones: primero, que las pruebas sean claramente mejorables y, segundo y muy importante, que estén disponibles para las partes. Si estás dos condiciones no se cumplen conjuntamente, entonces no habría lugar a la exclusión del elemento de juicio en cuestión. Evidentemente, a efectos de dicha valoración habría que considerar las circunstancias particulares del caso concreto, sobretodo porque a la parte sólo se les podría exigir que presenten la mejor información disponible para ellas.

Entre esas circunstancias cobra suma relevancia el elemento de los recursos económicos que las partes deberían invertir para incrementar la calidad de los testimonios periciales ofrecidos, pues habría que cuidar no incrementarles fuertemente los costos de un proceso judicial. Sin embargo, creo que la propuesta podría tener más sentido si nos enfocamos en los propios expertos que acuden continuamente a la arena jurídicoprocesal $^{63}$. Al menos a largo plazo, con la continua exclusión de las pruebas periciales que presentasen, estos expertos tendrían el incentivo de incrementar la calidad de la información que llevasen al proceso, teniendo incentivos para mejorar sus métodos, técnicas, etc. Por ejemplo, si los tribunales empiezan a solicitar información empírica sobre cómo de hecho funcionan las técnicas o métodos empleados por los expertos, no conformándose con meras explicaciones sobre cómo se supone que lo hacen, esto podría incentivar a los ciudadanos que pretenden ir a juicio alegando una prueba pericial

62 En su reconstrucción sobre la exigencia de valorar la fiabilidad de las pruebas periciales en la admisión en los Estados Unidos, esta opción sería la más importante: «Este tipo de consideración representa el principal, sino es que el único, razonamiento adecuado para la valoración de la fiabilidad contenida en la regla 702 [de las FRE]».

Vid. un desarrollo más amplio del principio de la mejor prueba disponible en NANCE (1988) donde hace referencia a la obligación colectiva de las partes en un proceso judicial de presentar un conjunto de elementos de prueba que haga lo más probable posible la hipótesis sobre los hechos del caso que defiende, por supuesto dentro de los límites que haya dados los costos y las características del contexto procesal. Es decir, se trata del requisito epistémico de disponer de las mejores pruebas en términos epistémicos: un conjunto de información, razonablemente disponible para las partes, que un juzgador de los hechos razonable encontraría adecuado para tomar una decisión fáctica.

Un caso típico, muy simple, de aplicación de este principio es la habitual solicitud a las partes para que presenten documentos originales en lugar de fotocopias de los originales.

63 Sobre la aplicación del principio de la mejor prueba disponible de NANCE al ámbito penal, fundamentalmente para las ciencias forenses, vid. REDMAYNE (2001: 133 y ss.). 
a buscar a expertos que cuenten con tal tipo de información lo que, a su vez, podría incentivar a los expertos a obtenerla.

Se trata, pues, de un criterio de admisibilidad que podría tener efectos positivos en la calidad de las pruebas periciales que tienen lugar en el proceso judicial siempre y cuando sea aplicable a todas las partes en todo proceso judicial. Es decir, con medidas como ésta se controlaría a las partes como categoría y no a un sujeto concreto que ha encendido la máquina jurídica procesal o está participando en ella.

Entonces, la economía procesal como restricción institucional con cierto compromiso con la averiguación de la verdad sugeriría al juez excluir pruebas periciales que en un caso concreto resulten más costosas que eficientes para su toma de decisión fáctica; mientras el control de las partes como facultad organizativa de los jueces llevaría a buscar que en los procesos judiciales entrasen las mejores pruebas periciales disponibles en un mercado asequible para las partes.

\section{A MANERA DE BREVE CONCLUSIÓN}

Hasta aquí se han analizado diversos criterios que podrían operar en la admisibilidad de las pruebas periciales de parte. Vale la pena concluir que el juzgador puede tomar en cuenta criterios jurídicos como la economía procesal, para excluir una prueba pericial cuyo aporte al conjunto de pruebas que ya se tiene sea menor (o considerablemente menor) que los costos que pudiese generar; o excluir aquellas pruebas periciales que entren en conflicto con la función de valoración de las pruebas que le corresponde de forma exclusiva. También puede considerar criterios epistémicos, administrando sus recursos cognitivos como agente que conoce y así evitar posibles peligros de desborde de información.

Ahora bien, el juzgador debe contemplar en todos los casos un criterio clave para admitir o excluir pruebas periciales: contar con información sobre la calidad de las afirmaciones periciales ofrecidas a efectos de poder realizar adecuadamente el juicio sobre los hechos, pues si no tiene esta información no podrá justificar el uso de tales afirmaciones en el razonamiento probatorio, sabiendo que las credenciales del experto no son suficientes para ello. Entiéndase bien, contra lo que muy habitualmente se afirma, no corresponde al momento de la admisión de la prueba valorar la calidad de las pruebas periciales, lo que deberá realizarse en el momento posterior de la valoración de la prueba. Para la admisibilidad, en cambio, resulta esencial controlar si se cuenta con información sobre dicha calidad, puesto que sólo una prueba que se acompañe de esa información podrá después ser valorada racionalmente por lo que se refiere a su fiabilidad.

Todos los criterios hasta ahora mencionados suponen un modelo de confianza hacia nuestros jueces, exigiendo de ellos un correcto razonamiento en su aplicación para conformar un conjunto de elementos de prueba adecuado cuando en éste haya información experta proporcionada por las partes. Y, a menos que justificadamente se disponga de otra cosa a nivel legislativo, los jueces deben valorar la calidad de las pruebas periciales en la etapa de valoración propiamente dicha. Entre otras cosas, analizando que no haya parcialidades cognitivas o disposicionales, las cuales son total- 
mente independientes de la parcialidad de origen del perito de parte que en sí misma no tiene porque suponer una disminución o aumento del valor probatorio de dicho elemento de juicio.

\section{BIBLIOGRAFÍA CITADA}

ABel Lluch, X., 2009: «La prueba pericial», en X. ABel Lluch y Picó i JunOY (dirs.), La prueba pericial, Barcelona: Bosch.

- 2012: Derecho Probatorio, Barcelona: JB Bosch Editor.

Alemany, M., 2005: «El concepto y la justificación del paternalismo», en Biblioteca virtual Miguel Ángel de Cervantes.

- 2006: El paternalismo jurídico, Madrid: Iustel.

Allen, R. J., y LeITER, B., 2001: «Naturalized Epistemology and The Law of Evidence», en Northwestern University School of Law, Public Law and Legal Theory Research Paper Series, Research Paper No. 01-8.

Allen, R. J., y NAFISI, E., 2010: «Daubert and its Discontents», en Brooklyn Law Review, 76.

Anderson, T.; SChum, D., y Twining, W., 2005: Analysis of Evidence, 2. ${ }^{a}$ ed., USA: Cambridge University Press.

AtienZA, M., 1988: «Discutamos sobre paternalismo», en Doxa, núm. 5.

BAYÓN, J. C., 2008: «Epistemología, moral y prueba de los hechos: Hacia un enfoque no benthamiano», en Analisi e diritto.

BotTer, T. I., 1982: «The Court-Appointed Impartial Expert», en M. D. Kraft (ed.), Using Experts in Civil Cases, 2." ed., United States of America: Practicing Law Institute.

Buglioli, M., y Ortún, V., 2001: Decisión clínica. Cómo entenderla y mejorarla, Barcelona: Springer.

CAlamandrei, P., 1945: Estudios sobre el proceso civil, Buenos Aires: Editorial Bibliográfica Argentina.

Coleman, J. L., 1992: Risks and Wrongs, Oxford: Oxford University Press. Citado por la traducción al castellano de D. PAPAYAnNis, Riesgos y daños, Barcelona: Marcial Pons.

Comoglio, L. P., 1980: Il principio di economia processuale, Padova: CEDAM.

Devis Echandia, H., 1972: «Cientificidad de la prueba, en relación principalmente con los dictámenes periciales y la libertad de apreciación del juzgador», en Revista de Derecho Procesal Iberoamericana, núm. 1.

DuCE, M., 2010: «Admisibilidad de la prueba pericial en juicios orales: Un modelo para armar en la jurisprudencia nacional», en D. ACCATINO (coord.), Formación y valoración de la prueba en el proceso penal, Chile: Abeledo Perrot Legal Publishing.

DwOrKIN, G., 2002: «Paternalism», en The Stanford Encyclopedia of Philosophy (Summer 2010 Edition). Disponible en bttp://plato.stanford.edu/archives/sum2010/entries/paternalism/.

DwYer, D. M., 2008: Judicial Assessment of Expert Evidence, Cambridge: Cambridge University Press.

EDmond, G., y Mercer, D., 2002: «Conjectures and Exhumations: Citations of History, Philosophy and Sociology of Science in US Federal Courts», en Cardozo Studies in Law and Literature, núm. 14.

FeInberg, J., 1986: Harm to Self, Oxford: Oxford University Press.

FERRER, J., 2007: La valoración racional de la prueba, Barcelona: Marcial Pons.

Garner, B. A. (ed.), 2009: Black's Law Dictionary, 9. ${ }^{a}$ ed., United States of America: West Publishing Co. 
GARZÓN VALDÉS, E., 1993: «¿Es éticamente justificable el paternalismo jurídico?», en Derecho, ética y política, Madrid: Centro de Estudios Constitucionales.

Gascón A. M.; Lucena Molina, J. J., y GonZÁlez RodríGueZ, J., 2010: «Razones científicojurídicas para valorar la prueba científica: una argumentación multidisciplinaria», en La Ley, núm. 5619.

Gigerenzer, G., 2006: «Heuristics», en G. Gigerenzer y C. Engel (eds.), Heuristics and The Law, United States of America: The MIT Press.

Goldman, A. I., 1991: «Epistemic Paternalism: Communication Control in Law and Society», en Journal of Philosophy, núm. 88.

Hart, H. L. A., 1966: Law, Liberty and Morality, Stanford: Stanford University Press. Citado por la versión castellana de M. A. RAMIRO AviÉs, 2006: Derecho, libertad y moralidad, Madrid: Dykinson.

Kahneman, D., 2011: Thinking, Fast and Slow, New York: Farrar, Straub and Giroux.

Keynes, J. M., 1920: A Treatise on Probability, Cambridge. Citado por la edición 2007, Watchmaker Publishing.

Laudan, L., 2006: Truth, Error and Criminal Law: An essay in legal epistemology, New York: Cambridge University Press. Citado por la traducción de C. VÁzQuez y E. Aguilera, 2013: Verdad, Error y Proceso Penal, Barcelona: Marcial Pons.

LeITER, B., 1997: «The Epistemology of Admissibility: Why Even Good Philosophy of Science Would Not Make for Good Philosophy of Evidence», en Brigham Young University Law Review, núm. 803.

LÓPEZ-MuÑIz. G. M., 2008: La prueba pericial. Guía práctica y jurisprudencia, 3. a ed., Madrid: Colex.

MANIACI, G., 2012: Contro il paternalismo giuridico, Torino: Giapichelli editore.

Montero Aroca, J., 1998: La prueba en el proceso civil, 2. ${ }^{a}$ ed., Madrid: Civitas.

Nance, D., 1988: «The Best Evidence Principle», en Iowa Law Review, 73.

— 2004: «Reliability and the Admissibility of Experts», en Seton Hall Law Review, vol. 34.

NiEva F. J., 2009: Jurisdicción y proceso, Barcelona: Marcial Pons.

McCormick, C., 1954: Handbook on the Law of Evidence, St. Paul Minnesota: West.

PÉREZ GIL, J., 2010: El conocimiento cientifico en el proceso civil: Ciencia y tecnología en tela de juicio, Valencia: Tirant lo Blanch.

Picó I JunOY, J., 2001: La prueba pericial en el proceso civil español, Ley 1/2000 de Enjuiciamiento Civil, Barcelona: Bosch Editor.

- 2007: El juez y la prueba. Estudio de la errónea recepción del brocardo iudex iudicare debet secundum allegata et probata, non secundum conscientiam y su repercusión actual, Barcelona: Bosch editor.

Posner, R., 1999: An Economic Approach to the Law of Evidence, John M. Olin Law \& Economics, Working Paper núm. 66. Disponible en http://www.law.uchicago.edu/files/files/66. Posner.Evidence.pdf.

Redmayne, M., 1998: «Admissibility Standards for Scientific Evidence», en I. MAdELLIN (ed.), Admissibility Evidence in Criminal Cases, Collected Papers.

- 2001: Expert Evidence and Criminal Justice, New York: Oxford University Press.

Roberts, P., y Zuckerman, A., 2004: Criminal Evidence, New York: Oxford University Press.

SARTORIUS, R. (ed.), 1983: Paternalism, Minneapolis: Minnesota University Press.

Schauer, F., y Spellman, B. A., 2013: «Is Expert Evidence Really Different?», en Notre Dame Law Review, 89, vol. 1.

SteIn, A., 2005: Foundations of Evidence Law, New York: Oxford University Press. 
SteIN, F., 1893: Das private Wissen des Richters. Untersuchungen zum Beweisrecht beider Prozesse. Citado por la traducción al castellano de A. DE LA OLIVA, El conocimiento privado del juez, Madrid: Centro de Estudios Ramón Areces, 1990.

Thayer, J. A., 1998: A Preliminary Treatise on Evidence at Common Law, Cambridge: Harvard University Press.

Tversky, A.; Kahneman, D., y Slovic, P., 1982: Judgment Under Uncertainty: Heuristics and Biases, Cambridge: Cambridge University Press.

Van DE Veer, D., 1986: Paternalistic Intervention, Princeton: Princeton University Press.

VÁZQUEZ, C., 2015: De la prueba cientifica a la prueba pericial, Barcelona: Marcial Pons. 